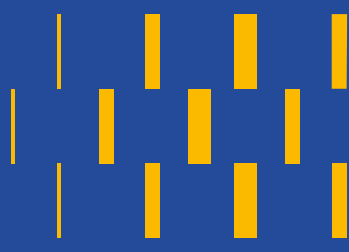

\title{
Reporte de viaje por el camino de Guillermo Cox desde Valdivia hacia el País de las Manzanas, siglos XVIII y XIX
}

\section{Travel report: the Guillermo Cox way from Valdivia to País de las Manzanas, 18th and 19th centuries}

Julio Esteban Vezub ${ }^{1}$ (D) https://orcid.org/0000-0001-6582-3663

Marcelo Godoy ${ }^{2}$ (D) https://orcid.org/0000-0002-3066-3900

Margarita Alvarado 3 (D) https://orcid.org/0000-0003-3308-0134

Simón Urbina ${ }^{4}$ (D) https://orcid.org/0000-0003-0825-2790

Leonor Adán ${ }^{4}$ (D) https://orcid.org/0000-0002-4486-6338

${ }^{1}$ Instituto Patagónico de Ciencias Sociales y Humanas, Consejo Nacional de Investigaciones Científicas y Técnicas, Puerto Madryn, ARGENTINA. Email: vezub@cenpat-conicet.gob.ar

${ }^{2}$ Dirección Museológica, Universidad Austral de Chile, Valdivia, CHILE.

Email: marcelogodoy@uach.cl

${ }^{3}$ Instituto de Estética y Centro Interdisciplinario de Estudios Interculturales e Indígenas (CIIR). Pontificia Universidad Católica de Chile, CHILE. Email: malvarap@puc.cl

${ }^{4}$ Escuela de Arqueología, Universidad Austral de Chile, Puerto Montt, CHILE.

Email: simon.urbina@uach.cl; ladan@uach.cl

\section{Resumen}

El artículo da cuenta de la exploración realizada por un equipo interdisciplinario y binacional durante 2015 entre Valdivia y el boquete cordillerano de Llifén, como parte de una investigación sobre las relaciones interculturales y territoriales en los asentamientos y rutas de la "Frontera de Arriba" de Valdivia colonial. Se siguió el itinerario de Guillermo Cox, quien buscaba una vía fluvial que conectara el Pacífico con el Atlántico en 1863, propósito impedido por los pehuenche del Limay (Neuquén), que no le permitieron continuar viaje hasta Carmen de Patagones (Argentina). Metodológicamente se realizó un contrapunto arqueológico, histórico, etnográfico y cartográfico que evidenció continuidades y variaciones del paisaje al cotejar el testimonio de Cox con los archivos misionales del tránsito del siglo XVIII al XIX y la historia regional reciente. El camino y la crónica decimonónicos fueron las fuentes principales para comprender las relaciones culturales, económicas y políticas entre hispano-criollos y mapuche en ambas vertientes andinas antes de la fijación de límites nacionales. Se sostiene como hipótesis que el proceso de colonización socioterritorial estaba avanzado en 1863, y que la población de la "Frontera de Arriba" era muy significativa, lo que explica los afanes del Estado chileno por terminar con su autonomía.

Palabras clave: Argentina, Chile, mapuche, interculturalidad, fronteras. 


\begin{abstract}
The article addresses the exploration conducted by a transdisciplinary and bi-national team in 2015 between Valdivia and the Llifén mountain gap, as a research on intercultural and territorial relationships in the settlements and routes of the "Frontera de Arriba" of colonial Valdivia. The itinerary followed was Guillermo Cox's, who searched for a river route connecting the Pacific with the Atlantic Ocean in 1863, a goal thwarted by the Limay Pehuenches (Neuquén) who prevented him from continuing his journey to Carmen de Patagones (Argentina). An archaeological, historical, ethnographic, and mapping counterpoint was used as methodology, which evidenced the continuities and variations of the landscape by comparing Cox's testimony with missionary archives of the movements during the $18^{\text {th }}$ and $19^{\text {th }}$ centuries, and recent regional history. The road and the chronicle were the main sources which enlight on the cultural, economic, and political relations between spaniard-criollos and mapuche at both sides of the Andes before the setting of national borders. The hypothesis proposed is that the social-territorial colonization process was already underway in 1863 and that there was a considerable population in the "Upper Border", a fact that explains the efforts made by the Chilean state to put an end to their autonomy.
\end{abstract}

Keywords: Argentina, Chile, mapuche, interculturality, borderlands.

Recibido: 30 marzo 2020. Aceptado: 24 septiembre 2020 


\section{Un proyecto de arqueología histórica}

En el marco de un proyecto centrado en la arqueología histórica de la ciudad de Valdivia, su jurisdicción colonial, y los territorios que se conocían en el reino de Chile como la "Frontera de Arriba", conformamos un equipo interdisciplinario y binacional que realizó trabajo de campo y revisión de archivos durante noviembre de 2015. ${ }^{1}$ Arqueólogos, antropólogos, estudiosos de estética e historiadores recorrimos los caminos de la provincia de Valdivia con dirección a la cordillera de los Andes. Nos guiamos con la crónica de Guillermo Cox, Viaje en las rejiones septentrionales de la Patagonia 1862-1863 (Figura 1), repitiendo el segmento del itinerario que siguió este explorador un 8 de febrero hacia los toldos del río Limay en "Las Manzanas", actualmente el sudoeste de la provincia del Neuquén, Argentina. Obligado a pagar un rescate por un carpintero y un peón que los caciques pehuenche le habían retenido como rehenes, Cox regresaba de un cruce inmediato anterior, comenzado en diciembre desde Puerto Montt por el paso de Peulla, ubicado más al sur en el actual Parque Nacional Pérez Rosales (región de Los Lagos).

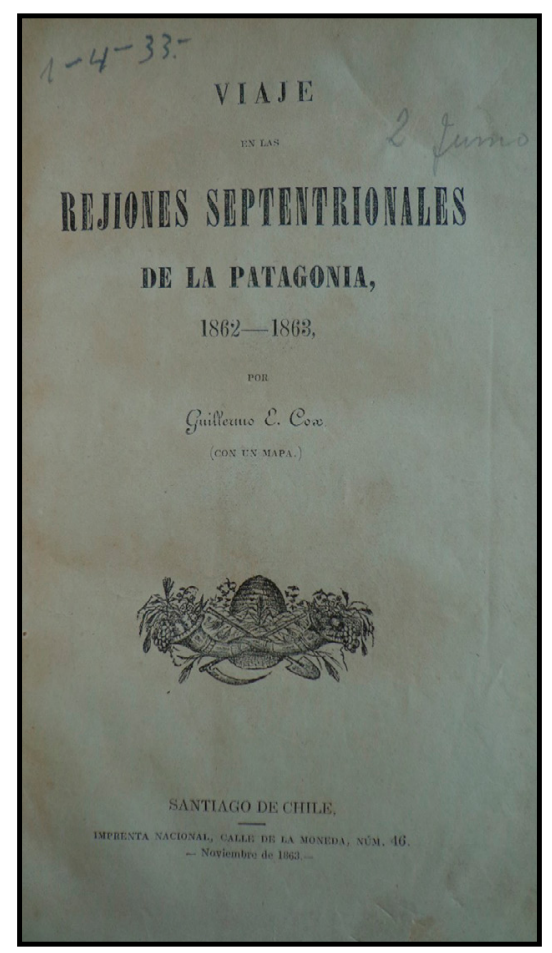

Figura 1. Portada original del libro de Guillermo Cox. Impresión realizada en Santiago de Chile, noviembre de 1863.

1 Proyecto FONDECYT 1130730 (2013-2015), "Arqueología histórica de la ciudad de Valdivia y su jurisdicción en el período colonial", y proyecto FONDECYT 1171735 (2017-2021), "Transformaciones e interacción en la Plaza Presidio de Valdivia durante el siglo XVIII, Chile". Investigadora responsable Leonor Isabel Adán A. 
Con las fuentes y cartografía en mano, fuimos cotejando documentación heterogénea y de distinta procedencia, afrontamos el viaje entre Valdivia y el boquete de Llifén o Lilpela, comparando la información que proporcionó Cox con nuestra interpretación de los hitos y los cambios del paisaje, el registro arqueológico e histórico de las fortificaciones, fundos, rukas, misiones y cementerios que hilvanaron este segmento del camino, además de otros vestigios de la red social por la que discurrió el cronista, que debió negociar con los referentes de esa trama para pasar de un punto a otro en el verano de 1863.

Completamos la prospección arqueológica y etnográfica con consultas a los archivos parroquiales de la Misión de Río Bueno y el Obispado de Valdivia, para comprender la densidad poblacional mapuche, que ofreció las condiciones de continuidad y diferenciación social que atestiguó Cox a medida que se internaba hasta trasponer la cordillera Nevada para arribar al Puelmapu o "País del Este".

Concebido como reporte de viaje, se presentan en este artículo los resultados de nuestra exploración, se plantea la centralidad que tuvo el eje comunicacional Valdivia - Carmen de Patagones desde la fundación de la segunda sobre el Atlántico en 1779, y en virtud de esto, la asociación que hubo entre el proyecto de Cox con las expectativas del Estado chileno de prolongar la colonización de la Araucanía al este de los Andes, para lo cual contó con el aval del intendente de Llanquihue y el interés directo del presidente Manuel Montt. ${ }^{2}$ Al constatar que Cox no se aventuró en el vacío, y que transitó circuitos previamente conocidos sobre los que estaba bien informado, sostenemos dos hipótesis: primera, que pese a la percepción de Valdivia como un enclave en el corazón de la autonomía mapuche y las condiciones de alteridad radical que describe la crónica, el grado de colonización socioterritorial era significativo en 1863, y, segunda, que la demografía de la región de los Ríos que lleva desde el Pacífico hacia las montañas era importantísima, y de ahí las ambiciones Estado-nacionales por transitarla y poner fin a su autonomía. Al cotejar la exploración propia con el relato del viajero intentamos dilucidar por qué razón Cox enfatizó la supuesta condición de alteridad. Si Valdivia era un espacio de colonización campesino, militar y misional desde la reconquista de Osorno en 1793 y la acción franciscana, ¿lo hizo para promocionar los proyectos colonizadores o porque efectivamente ingresaba en un territorio autónomo, y por lo tanto radicalmente diferente y dominado por otras pautas políticas y culturales a medida que se internaba en los Andes?

El objetivo principal del proyecto que enmarcó nuestro viaje fue, entonces, caracterizar desde la perspectiva de la arqueología histórica las relaciones interculturales de hispanos e indígenas de la ciudad de Valdivia, y la inserción de esta en el contexto del reino de Chile y la administración colonial. Si la incorporación al equipo de estudiosos trasandinos buscaba abandonar el aislamiento interpretativo en el que generalmente incurrieron los antecedentes, la experiencia de terreno mostraría que antes que una perspectiva comparativa, se trataba de integrar en un marco de análisis común una variable espacial más amplia, y a la vez diversa, que reconociera los niveles de continuidad y discontinuidad regional mapuche como parte de procesos que involucraban ambos lados de la cordillera, superando las parcelas trazadas por cada historiografía y arqueología nacionales. Constatar la existencia de espacios por fuera de la soberanía colonial a mediados del siglo XIX no significa postular una continuidad territorial mapuche que, como

2 El colono alemán Francisco Fonck, amigo personal de Cox, comentó que el presidente Manuel Montt le había extendido pasaporte para realizar el viaje (1896, p. 297). El seguimiento oficial de la expedición se confirma con las notas del intendente de Llanquihue, Gaspar del Río, remitidas al gobernador de La Unión desde Puerto Montt, el 14 y el 27 de enero de 1862, Archivo Nacional de Chile (en adelante ANCh), Gobernación de la Unión, vol. 3, 1841-1868. 
sostiene Álvaro Bello (2011), solo se daba a través de la integración virtual y simbólica de segmentos regionales, y la asociación de nodos distantes de parentesco, política y comercio en el plano estructural.

¿Por qué recurrir al registro de un viaje de exploración a territorio autónomo mapuche, pehuenche y tehuelche del siglo XIX para responder preguntas de un proyecto que trata en lo fundamental de la arqueología de una plaza española del siglo XVIII? La crónica misma proporciona respuestas, tanto espaciales - al mostrar que la colonización se desplegaba sin limitarse al enclave valdiviano, siguiendo caminos mapuche que conectaban un sistema de misiones, fortalezas y chacras que, a su vez, copiaban los cursos fluviales- como argumentos temporales -al presentar los interlocutores y mediadores que le informaron a Cox sobre quiénes y qué encontraría más adelante-. Este fue el caso del "viejo Olavarría”, que le narró su experiencia de la década de 1790 acompañando al padre Menéndez en sus misiones transcordilleranas: "cosa increíble que después de setenta ańos, este anciano tuviese la memoria tan fresca", se sorprende Cox (1863, p. 72), quien a su vez se hizo guiar por Vicente Gómez, el nieto de Olavarría que también había divisado el lago Nahuel Huapi desde las alturas, valiéndose de los datos de su abuelo para guiar a Francisco Fonck y Fernando Hess en 1856. Estos colonos documentaron su expedición, antecedente de la que seguirá Cox por la misma ruta, los lagos Llanquihue y Todos Los Santos, el río Peulla, y el abra norte del cerro Tronador (Fonk y Hess, 1857). Todos ellos estuvieron muy relacionados y contaron con los mismos baqueanos. Fonck recuerda sobre esa exploración de 1856, “...la primera que desde el tiempo de Menéndez avanzara hasta el lago", cuando no encontraron habitantes, y encendieron una fogata en la península de San Pedro que motivó reproches ante un vecino prestigioso de Osorno por parte de Llanquitruz, el gran jefe "pampa" con territorialidad sobre Nahuel Huapi (Fonck, 1896, pp. 337-338).

Como evidencia de los cambios de la década de 1850, Otto Muhm, otro colono valdiviano que había visitado los toldos de Llanquitruz en Puelmapu, contó a Cox que este le había dicho que "en el tiempo que gobernaba mi padre, no vino ningún espańol por acá, pero ahora vienen" (Cox 1863, p. 176). ${ }^{3}$ Veinte años antes y sin cruzar la cordillera, Allen Gardiner había remontado el río Calle-Calle, visitando Antilhue, Quinchilca y Futrono. Este marino británico y pastor protestante advirtió la profundidad de la interpenetración colonial, el catolicismo, y la mediación de agentes estatales en la política mapuche, entre ellos el "Comisionado o Guardián de los Indios” Francisco Aburto (Gardiner, 1841, p. 121), y los miembros de la familia Agüero que se mencionarán en este artículo. No obstante, destacó la dificultad para determinar hasta dónde se extendía la influencia del gobierno chileno, y la prevalencia de una "tierra neutral" hasta un lago que permanecía "imperfectamente explorado", según sus informantes, y que Gardiner conjetura que podría ser el Nahuel Huapi, a dos días de Osorno (1841, p. 140).

Distintas investigaciones han destacado los nexos entre Valdivia y Carmen de Patagones que perdurarían atravesando esa "tierra neutral" con la mediación de los indígenas hasta las campañas de expansión de los Estados y la constitución efectiva de las fronteras del último cuarto del siglo XIX, así como el papel del corredor de los ríos Limay-Negro como eje comunicacional, económico y político de la Patagonia (Bustos, 1993; Pinto, 1996; Villar y Jiménez, 2003;

3 Bello (2011, pp. 151-165) señala que el ingeniero y cartógrafo alemán Wilhelm Frick, a sueldo del gobierno de Chile, dedicó varios años a buscar pasos hacia las pampas argentinas, especialmente el de Villarrica (Mamüil Malal o Tromen). Publicó varios informes y publicaciones, y fue quien aportó la mayor cantidad de datos sobre el boquete de Hua-Hum o Riñihue, muy cercano al de Lilpela, aunque habría ignorado este último, quizá por su interés en la búsqueda de una vía navegable hacia el oriente e los Andes como parecía proporcionar Hua-Hum. 
Bechis, 2008; Alioto, 2011; Foerster y Vezub, 2011). Los hispanocriollos buscaban remover las jefaturas mapuche y tehuelche que disputaban las vías de circulación de personas, ganado, mercancías e información que conectaban el océano Pacífico con el Atlántico, tal como se plantea en un trabajo de arqueología histórica en el que se sistematizan diez sitios de carácter defensivo del tipo fortines en el área cordillerana, situados para el control de los pasos al norte y sur del volcán Villarrica, Mamüil Malal, Liquiñe y Hua Hum, entre los cuales se distinguen dos emplazamientos de plantas cuadradas atribuibles a hispanos, y ocho plantas circulares que se definen como de adscripción indígena (Mera, Lucero, Vásquez, Harcha y Reyes, 2004). Esta información es congruente con la disponible al este de los Andes, que propone la tesis de un sistema logístico y de control territorial para las actividades comerciales entre ambas vertientes, al disponer de evidencia arqueológica de un conjunto de corrales y recintos habitacionales para el control de pasos en los valles de los ríos Malleo y Haichol (Goñi, 1986-1987). Otros estudios del registro arqueológico muestran que la cuenca del río Valdivia y su fuente trasandina del lago Lácar (Pérez, 2016) fueron una unidad regional desde por lo menos mil años, así como la continuidad social entre el Alto Biobío con el valle del Collon Curá (provincia del Neuquén), destino final de Cox. Conforme a estas investigaciones la integración de poblaciones y paisajes se remonta varios siglos sin que la cordillera significara un límite natural, ni tampoco territorial, como también se desprende de la morfología del arte parietal que está presente en ambos lados (Boschín, 2009). Inmediatamente al sur de la variable espacial de este estudio, Bellelli, Podestá y Scheinsohn (2008) verifican el mismo tipo de movilidad transcordillerana. Describen el valle fluvial del Manso - El León (Argentina y Chile, respectivamente), que permite su tránsito regular, según consta en la documentación histórica y arqueológica, que muestra la correspondencia del arte rupestre en ambos lados de la cordillera.

De ahí la importancia de la crónica de Cox para retroceder en el tiempo. Se trató de una exploración de inteligencia en el sentido amplio de la época, que combinaba propósitos científicos, geográficos y sociológicos declarados con otros geopolíticos. Cox buscaba develar el secreto mejor guardado por las jefaturas mapuche huilliche o pehuenche del "País de Las Manzanas" al intentar abrirse paso por el segmento del camino que ningún español, chileno ni argentino había conseguido recorrer completamente entre Valdivia y Carmen de Patagones durante la autonomía territorial de los siglos XVIII y XIX. Este impedimento en la circulación de huincas, extranjeros, o gente difícil de clasificar con criterio etnológico, no regía para los circuitos informales que recorrían caravaneros y mediadores políticos y comerciales, que dejaron registros escasos y a menudo velados. La presencia de lenguaraces, escribanos y soldados en el entorno de los fuertes de Carmen de Patagones y Bahía Blanca desde la década de 1830, y las secuelas en Pampa y Patagonia de la "Guerra a Muerte", ${ }^{4}$ son indicios de esos permisos diferenciales que los lonkos otorgaban a quienes los beneficiaban con su diplomacia, capacidades técnicas y servicios.

No deja de ser curioso que hasta su nueva edición en el marco de la "Biblioteca Fundamentos de la Construcción de Chile", publicada para el bicentenario de las revoluciones de independencia, la crónica de Cox haya despertado más interés en la historiografía, etnología y arqueología argentinas que en sus pares chilenas, o incluso mapuche, hecha excepción de la lectura atenta de Bello (2011) y las investigaciones de Carreño Palma (2005) sobre el abasto con ganado del Puelmapu a las curtiembres valdivianas, y la complementariedad de esta industria

4 La "Guerra a Muerte" de la década de 1820 fue una continuación de las guerras de independencia en la Araucanía autónoma. Los líderes mapuche se alinearon con los bandos realista e independentista según sus propios enfrentamientos (Villar y Jiménez, 2003). 
con las destilerías que producían aguardiente para intercambio. Esto fue así pese a que el libro había sido publicado en 1863 por una imprenta de Santiago, y que su aparición había sido adelantada por entregas en El Araucano. Esta atención escasa operó como si la aventura hubiese transcurrido exclusivamente en el Puelmapu, como si la frustración del proyecto colonizador chileno que planteaba llegar al río Negro le quitara aliciente a una lectura que informa muchísimo sobre el paisaje social y su metamorfosis al internarse en la cordillera desde el Pacífico, tema que es el principal objeto de análisis de este artículo.

Cox viajó dos veces por esta frontera sin traza en el verano de 1862-1863, con recorridos distintos, el primero desde Puerto Montt por el lago Llanquihue y el río Peulla, cruzando los Andes por el cerro Tronador. Después de construir y botar una balsa en el lago Nahuel Huapi, naufragó en los rápidos del Limay, fue capturado con su comitiva por gente de Paillacán el 8 de enero, y no pudo completar el plan de navegar hasta Carmen de Patagones. Fue forzado a regresar a Chile, esta vez a Valdivia, para reunir "regalos" que pagaran el rescate de los peones retenidos. La ida y vuelta del segundo viaje fue por la misma ruta utilizada en su regreso desde Puelmapu en el primero, el boquete de Llifén. Este fue el recorrido que seguimos en 2015, y que se detalla con línea azul entera en los mapas (Figura 2 y Figura 9). Antes y después, 2011 y 2017, transitamos una parte del tramo de Cox en el actual territorio argentino hasta el paso internacional de Hua-Hum, desviándonos hacia el lago Pirehueico como obliga el camino habilitado, sin poder cubrir el segmento entre los lagos Nonthué y Queñi en Neuquén (línea azul punteada en los mapas), y el fundo Santa Rosa que se interpone a $4 \mathrm{~km}$ del paso del lado chileno por las razones que se explicarán.

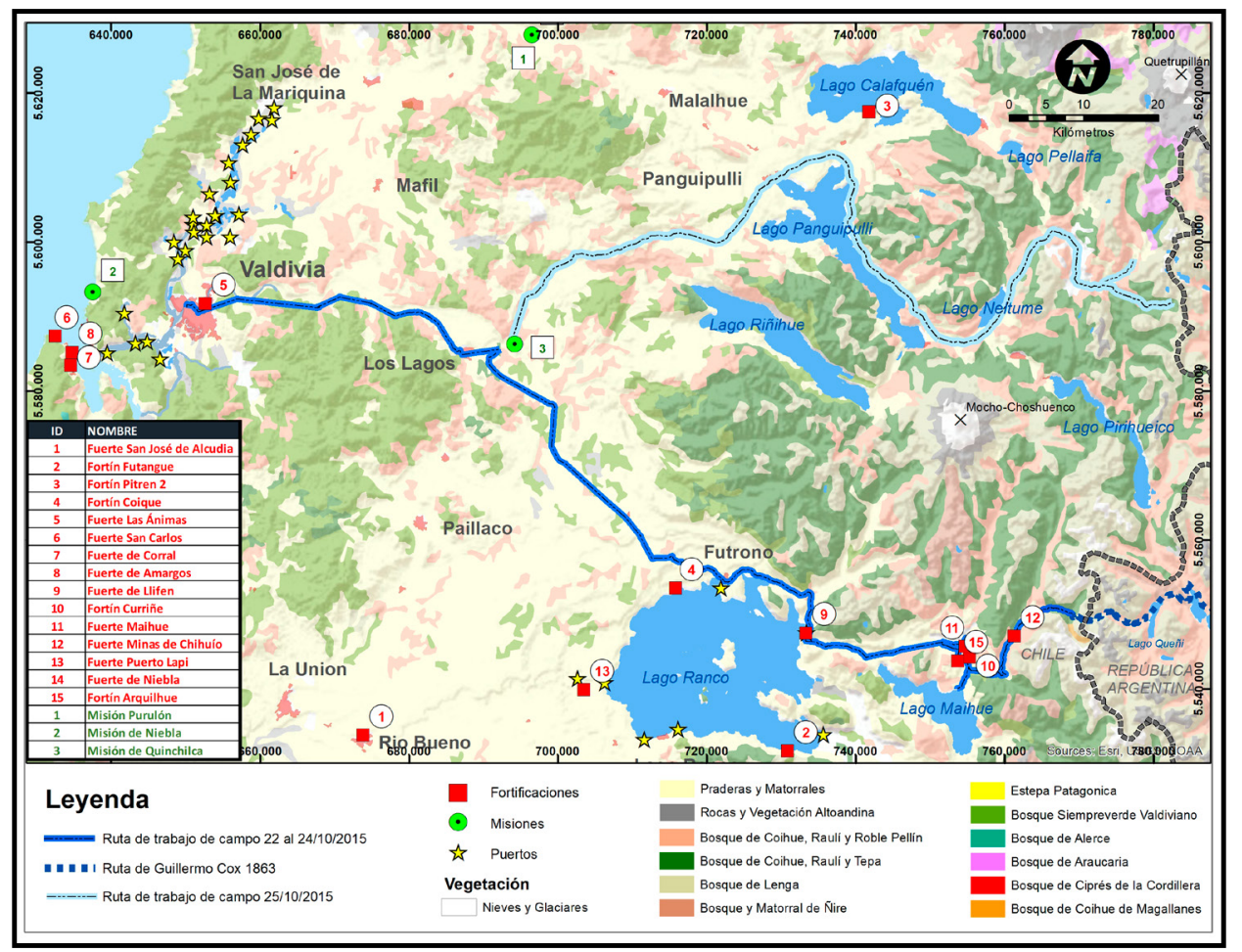

Figura 2. Cartografía del recorrido siguiendo el trazado de Guillermo Cox.

Registro GPS a partir de las referencias de Cox. Provincia de Valdivia, región de Los Ríos, Chile. Fuente: Elaboración propia. 
Viaje en las rejiones septentrionales... está dedicada a Woodbine Parish, el diplomático que impulsó el Tratado de Amistad, Comercio y Navegación entre Gran Bretaña y las provincias rioplatenses y que reconoció la independencia de estas en 1825. Cox justificó su dedicatoria por el estímulo que le dio la lectura de un libro de Parish, quien había señalado en 1839 “...las inmensas ventajas que podrían reportar las dos Repúblicas de Chile i del Río de la Plata con la posibilidad de una comunicación entre el Océano Atlántico i la Cordillera por medio del Río Negro i del lago de Nahuelhuapi". La libre navegación de los ríos era la política que instrumentaban las potencias europeas y las élites nacionales para abrir el "corazón de las tinieblas" de los continentes colonizados a la penetración del Estado y el capitalismo, parafraseando la novela de Joseph Conrad. El Estado nacional chileno buscó tempranamente allanar los territorios fuera de control. González Díaz (2017) describe las acciones realizadas desde Valdivia hacia el antiguo enclave hispano de Villarrica, la exploración de Ignacio Domeyko en 1845, que propuso instalar una misión, una pulpería, la designación de capitanes de indios amigos y proyectar una ruta comercial entre Villarrica y San José. En 1848 otra expedición dirigida por Ignacio Agüero con el apoyo de jefes indígenas de las parcialidades de Pitrufquén, enfrentados con otros, dio con las ruinas de la antigua Villarrica, iniciando el proceso gradual de ocupación que recién se impondría en la década de 1880.

Dentro de este marco de interpretación, es objetivo del artículo comprender la territorialidad fronteriza y la dinámica de circulación mediante la reconstrucción histórica del camino hacia y desde el boquete de Lilpela como parte del sistema de vías transcordilleranas mapuche del siglo XIX. Se intentará entender las lógicas, dificultades y permisos con que Cox hilvanó sus viajes, y detectar los hitos y usos del paisaje que subsisten actualmente, reconociendo los conceptos que están presentes en la documentación para organizar la percepción espacial y social, como por ejemplo "los indios de la montaña" que registraban los archivos parroquiales. Por último, se buscará profundizar el conocimiento de las relaciones que fueron interrumpidas por el proceso de cristalización de las fronteras nacionales, recuperando otros modos de viajar y descubrir las marcas históricas del paisaje. Para cumplir con estos objetivos, primero se revisarán los antecedentes y se presentará la metodología, dedicando la parte principal del artículo a la descripción del viaje de campo. Esto se cotejará y ampliará con las fuentes de archivo y con las observaciones arqueológicas y etnográficas de un itinerario que enlaza los siglos XVIII y XIX con los acontecimientos y las memorias de la historia reciente.

\section{Antecedentes y metodología: el camino como fuente principal}

Después de la atención que le prestó la etnología argentina a Cox (Vignati, 1942; Harrington 1946; Escalada, 1949; Casamiquela, 1965) como fuente para las clasificaciones étnicas y lingüísticas, fue Boschín (1975) quien lo valorizó en términos arqueológicos e históricos, referenciando los toldos del Limay que Cox visitó, y el coto de caza donde acompańó a sus anfitriones, volcándolos en una cartografía. Navarro Floria (2012) resituó la crónica en el marco de los estudios de frontera, proponiendo una caracterización original sobre el País de las Manzanas como un "patio trasero" indígena desde la perspectiva de Buenos Aires. Previamente, Nacuzzi (1998) cuestionó el modo en que la etnología de mediados de siglo XX se ubicó en línea con las clasificaciones étnicas que proporcionaba Cox, oponiendo una lectura que resalta la necesidad de considerar la movilidad fluvial y transcordillerana en Norpatagonia, así como la formación de jefaturas en la construcción histórica de identidades y territorialidades. Desde entonces distintos trabajos abrevaron en Cox, incluida la investigación sobre la jefatura de Valentín Saygüeque, que incluyó la reconstrucción del complejo de caminos que controlaban este 
lonko, sus allegados y antecesores, y el sistema de relaciones políticas, comerciales y epistolares que atravesaban los Andes (Vezub, 2009).

Metodológicamente, realizamos viajes de reconstrucción de caminos con las crónicas como fuentes para confrontar paisajes (Figura 3), fotografías de topógrafos militares durante las campañas de conquista (Vezub, 2017), y cartografías e inspecciones de tierras del interior patagónico (Chávez, Vezub, Cinti y Bocco, 2021). ${ }^{5}$ El proyecto encabezado por Leonor Adán sobre arqueología histórica de Valdivia y su jurisdicción buscó indicadores arqueológicos y etnográficos que evidenciaran la intensidad de las relaciones a ambos lados de la cordillera en períodos coloniales y anteriores (Hadjuk y Cúneo, 1997-1998; Berón, 2017). Valdivia representaba un caso óptimo para desarrollar esta aproximación relacional e interdisciplinar, puesto que los estudios históricos clásicos ofrecían datos significativos como los de Guarda (1953, 1980, 1990, 2001; Guarda y Moreno J., 2010), además de contar con investigaciones arqueológicas previas sobre los sitios históricos coloniales como los de Van de Maele (1968).

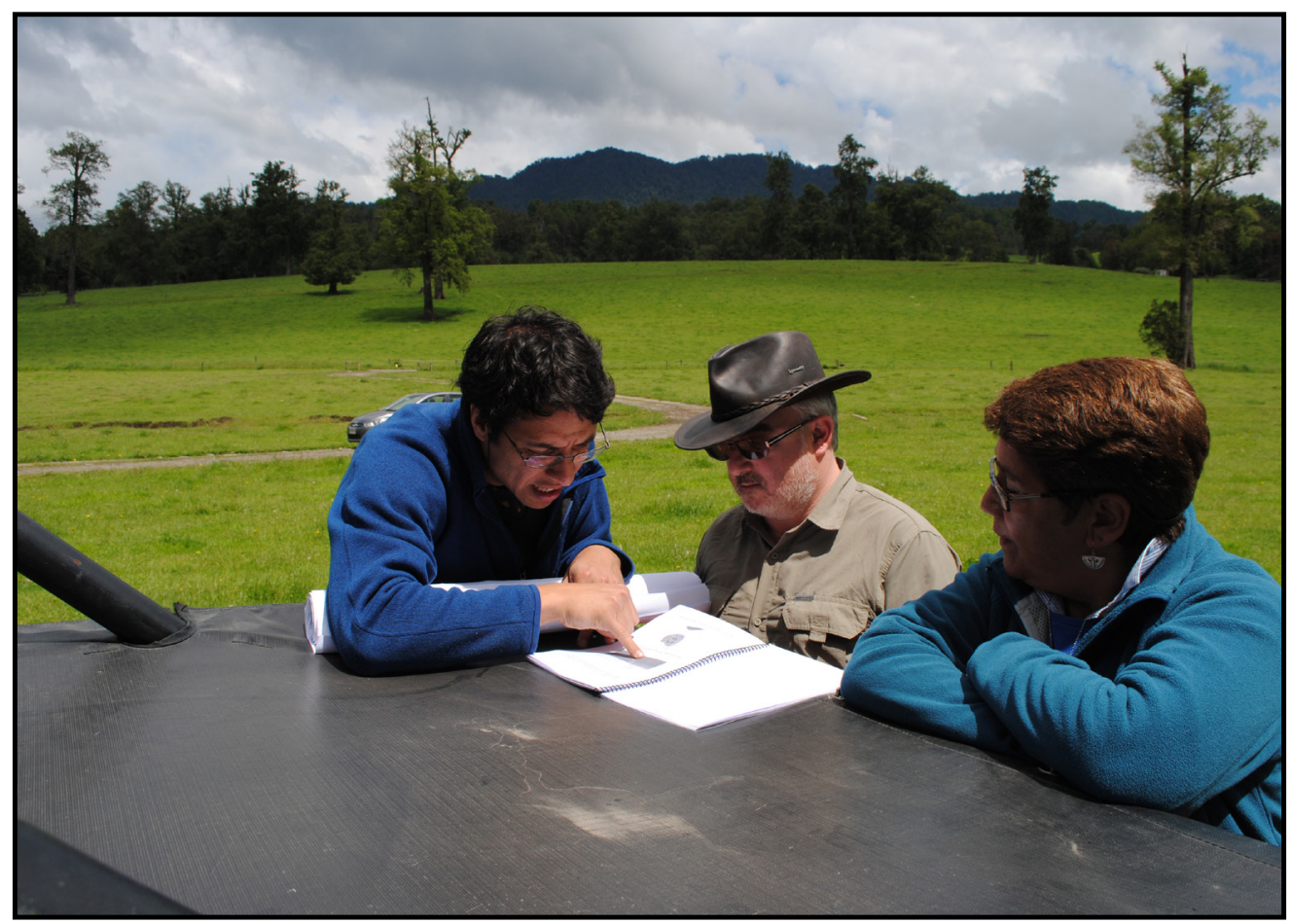

Figura 3. Trabajo de campo y contrapunto entre la crónica Cox y el registro cartográfico. El equipo de investigación revisa las referencias cartográficas en el sitio Fortín Arquilhue. Fotografía: Marcelo Godoy.

5 Melo, Jiménez y Alioto (2016) identificaron la ruta de $1450 \mathrm{~km}$ que siguió el cacique Llampilanguen desde Trupf-Trupf en la actual región de La Araucanía chilena hasta la laguna del Monte en la provincia de Buenos Aires en 1804, valiéndose de fuentes históricas y cartográficas con toponimia mapuche, y observación de la disponibilidad de fuentes de agua. 
Como se planteó al formular el proyecto, el acercamiento ocurre desde la práctica de la arqueología, y enfatiza la comprensión del asentamiento, el territorio y las materialidades, tanto las hispanas como indígenas, basándose en fuentes históricas. Se practica una arqueología que busca contribuir a la historia, la etnografía, y establecer puentes y diálogos entre estos campos disciplinarios para relevar las relaciones interculturales o interétnicas en un período en que las investigaciones históricas han privilegiado mayoritariamente la comprensión de los procesos desde el punto de vista hispano en la vertiente del Pacífico. De esta manera, se identifica un área de estudio por criterios históricos y biogeográficos más amplios, y se sostiene que el ordenamiento colonial que se organizaba desde Valdivia se asentaría en uno indígena preexistente.

Paul Treutler (1861), contemporáneo de Cox, describió los sistemas de movilidad de las jefaturas indígenas de Valdivia y Panguipulli, y el tipo de vínculo que había entre asentamientos y cuerpos de agua. Esta será la hipótesis de Bengoa (2008) para explicar que la población de los "antiguos mapuches" previa a la conquista se distribuía siguiendo las cuencas hídricas. Ello dialoga con el estudio de Bello (2011) sobre los ñampulkafe, o viajeros mapuche que combinaban los roles de guerrero, "maloquero" o comerciante como actores clave en la integración sociocultural de un territorio de segmentos discontinuos y distantes. Para comprender esta organización socioterritorial rizomática, Bello emprendió travesías con José Ancán, reconstruyendo el itinerario de Pascual Coña, lenguaraz de una comitiva de lonkos que cruzó la cordillera para parlamentar en el Puelmapu y Argentina en el contexto de las campańas militares de 1880. Bello puso a prueba una metodología que hoy es modelo para los estudios de pasos y caminos y la integración histórica de la territorialidad mapuche (Bello, 2011, pp. 38-39), además de dedicar un apartado de su libro al boquete de Ranco o Llifén, donde analiza la crónica de Cox, y anticipa la dinámica de permisos o habilitaciones que debió lograr el expedicionario, y la observación sobre el rosario de chacras donde solo encontró mujeres, ya que los hombres estaban de travesía con sus "conchavos" ganaderos al otro lado de la cordillera.

Una investigación sobre la dinámica de distribución de los bosques en la cuenca del río Valdivia y su relación con los procesos territoriales, encarada desde la historia ambiental (Camus y Solari, 2008; Solari, Cueto, Hernández, Rojas y Camus, 2011), es otro antecedente directo. Los autores sugieren que la colonia hispana temprana produjo cambios demográficos derivados de la explotación inescrupulosa de mano de obra y las enfermedades importadas. Señalan que la pérdida de vidas afectó la composición del paisaje, cambiando parajes con abundante población indígena que se localizaba en claros cercanos a cuerpos de agua en el siglo XVI, a zonas densamente boscosas con poblaciones reducidas a inicios del siglo XIX. Esta investigación es importante no solo por cómo combina fuentes historiográficas con arqueológicas para el análisis cartográfico del poblamiento, sino también por el papel que se reconoce al desarrollo de los caminos. Nuestro reporte enriquecerá el mapa que publicaron sobre la importancia de las rutas según la frecuencia de las citas históricas del siglo XIX, aumentando el registro de las que se internaban y atravesaban la cordillera.

Otro trabajo (Delrio et al., 2018) plantea la dimensión procesual de las construcciones de territorialidad en Norpatagonia desde un enfoque que difiere del nuestro, estableciendo similitudes y diferencias entre el caso de Cox y otras cinco crónicas contemporáneas, protagonizadas por un europeo, dos argentinos y dos mapuche (Musters, Bejarano, Moreno, Cońa, Katrülaf). Aportan a la localización de los hitos descritos por Cox, así como la comprensión del "circuito encadenado de escalas-casas-hospedajes". No obstante, la imaginación de "cartografías significativas para distintos sujetos" es principalmente ideológica, y proyectiva. Se pasa por alto que la mayoría de dichos viajeros, incluido Cox, produjeron y acompañaron sus relatos con 
representaciones cartográficas efectivas, es decir, croquis y mapas, que no se toman en cuenta como objeto de análisis ni se condicen con estos otros que se desprenderían de los textos de cada viajero, que, salvo en los casos mapuche, estarían condicionados por su "proyecto racista" (Delrio et al., 2018, p. 20), o por visiones estatales de las fronteras. El artículo incluye el dibujo de mapas hipotéticos que son elaborados por los autores a partir de lo que interpretan de cada lectura, sin confrontarlas con el registro cartográfico que anexaron Cox, Musters, Bejarano y Moreno ni con lo que cada uno de estos cronistas identificó sobre el terreno. Se privilegia la caracterización de lo que denominan "cartografías exóticas" (Delrio et al., 2018, p. 18), que subestima las ambivalencias de la experiencia colonial y sus esfuerzos por conocer incluso dentro de los paradigmas de época, confundiendo la fuente histórica con su interpretación. La elaboración cartográfica, al carecer de una unidad de estilo definida, nomenclatura e información como cotas y cuerpos de agua, dificulta la comparación visual para el análisis territorial y de movilidad, dando por resultado mapas exclusivamente políticos, o Estado-nacionales, sin adecuación con la geografía histórica que tendrían como referente a partir de cada crónica.

Proponemos, en cambio, interpretar las fuentes a ras del suelo, a medida que se desanda el camino, recuperando la relación que establece la cartografía como representación con los lenguajes propios del choque etnográfico, su registro en las toponimias, y el reconocimiento de poblaciones y paisajes. Como se plantea en un artículo sobre caminería atlántica patagónica (Bocco, Cinti, Vezub, Sánchez-Carnero y Chávez, 2019), pensados como "lugares en movimiento", la etnografía sugiere que los caminos son, en sí mismos, lugares. Sinónimos de conexión, están imbuidos en el significado de la actividad que ocurrió a su largo. Como se plantea en dicho estudio, moverse a través de un paisaje es un proceso de compromiso donde los caminantes reafirman vínculos con la topografía y el ambiente construido, así como con las relaciones que de ellos se desprenden, y el conocimiento para interpretarlos.

A la luz de las hipótesis sobre el conocimiento previo, el grado de colonización y la importancia demográfica de la región, la experiencia de Cox es una vía de acceso a las concepciones diferentes del habitar y las formas de apropiación del espacio, tanto por parte de mapuche como no mapuche. La pregunta sobre dónde se insertan las prácticas y sentidos del habitar de las distintas sociedades y culturas podría ser en parte respondida si se consideran las superposiciones, desplazamientos y rupturas que implican estas dos maneras de ocupar y apropiarse de lugares y paisajes. Como se dijo, esta observación la hicimos con la crónica y la cartografía en mano, confrontando el texto con cada recodo del camino, la información etnográfica, y la combinación de fuentes de distinta tipología: toponimia, cementerios, archivos parroquiales, o la correspondencia de Saygüeque que contiene menciones a los parajes y los actores que conoció Cox.

Para este artículo se utiliza parcialmente la información de su viaje al este de la cordillera. Nos concentraremos en su trayecto de regreso desde Valdivia para rescatar los rehenes, respetando la reconstrucción hecha durante nuestro propio viaje de 2015. El trabajo no se limita a una visión nacional fronteriza, cabe aclarar, pero sí al impedimento de trasponer el límite entre Chile y Argentina, ya que quedó un tramo de $25 \mathrm{~km}$ en la más alta cordillera que no se pudo recorrer desde ninguno de los dos países (lago Queñi, Neuquén en Argentina hasta ingreso a paso Lilpela, lago Ranco, Chile). 


\section{Por el camino de Valdivia al boquete de Llifén}

$\mathrm{Al}$ ser parte de un proyecto más amplio sobre la arqueología histórica de Valdivia, tanto en la variable espacial como en la periodización, los preparativos del trabajo de terreno para reconstruir el viaje de Cox incluyeron un taller en la Universidad Austral durante los días previos. Ello permitió situarse en contexto, discutir cómo relacionar la crónica de 1863 con los siglos anteriores, y encontrar denominadores comunes de metodología entre disciplinas y especialidades. ${ }^{6}$ Esto incluyó visitas a los sitios arqueológicos de costa y al patrimonio histórico valdiviano como la misión de Cristo Crucificado en la costa de Niebla, y los fuertes de San Carlos y San Sebastián de la Cruz en la comuna de Corral.

En el taller se discutió el sentido de las identificaciones como "frontera de arriba" (Urbina, 2005, 2009), concepto hispanocolonial que llamaba "subir" al ascenso ordinal en latitud de norte a sur. La documentación sitúa en la frontera de arriba los emplazamientos entre los ríos Toltén, por el norte, y Maipué, por el sur, el Pacífico por el oeste, y el área del lago Nahuel Huapi en la actual Argentina. Esta definición resultó clave para emprender el viaje, así como su relación con el léxico hispánico presente en otras expresiones como "cordillera fragosa", que evidencia una concepción estética del territorio y las formas de habitar. Asimismo, que imaginar un paisaje no es lo mismo que visualizarlo, y que los españoles colonizaron con esta impronta ideológica y a la vez sensorial que también presentan los mapuche para caracterizar las relaciones con el ambiente. Por ejemplo, Guadalafquen, el topónimo original del entorno donde fundaron Valdivia, significa 'ciénaga' o 'pantano' (Adán, Urbina y Alvarado, 2017). Que la instalación de la plaza de armas haya sido sobre el trazado de una cancha de juego de palín ${ }^{7}$ repitió un patrón de colonización que se apoyó en el control de lugares de relevancia ceremonial, política y económica preexistentes.

Conceptos como repü o 'camino', y sus aumentativos o calificativos, pichi repü, futa repü, cheque repü o "camino secundario", etcétera, y la caminata como unidad de medida, adquirieron relevancia para la travesía (Godoy, 2014). El 22 de noviembre de 2015, a poco de iniciar el recorrido hacia el este por el río Calle-Calle, contrastaríamos las descripciones de Cox con el sentido domesticado del paisaje, extremado después de 150 años, pero que ya estaba destacado en el Mapa de una parte de Chile, que comprehende el terreno donde pasaron los famosos hechos entre Españoles y Araucanos, autoría de Tomás López (1777), donde se registra la abundancia de pueblos de indios y chacras sobre los ríos (Figura 4), evidencia que se repite en la documentación eclesiástica de los siglos XVIII y XIX.

6 Taller de Investigación Valdivia: Relaciones interculturales y transandinas en el periodo Colonial. Realizado en Casa Luis Oyarzún, Dirección de Vinculación con el Medio UACh, 20-21 de noviembre 2015, Valdivia.

7 "En medio desta tierra, estaba una larguísima carrera de cuatrocientos pasos, donde los indios jugaban a la chueca, y entrando el gobernador por ella, siguiéndole los suyos, comenzó a pasar la carrera diciendo a voces con gran regocijo 'aquí se fundará la ciudad de Valdivia', cual otro Rómulo que intituló a Roma con su mismo nombre" (Mariño de Lobera, 2003, p. 105). 


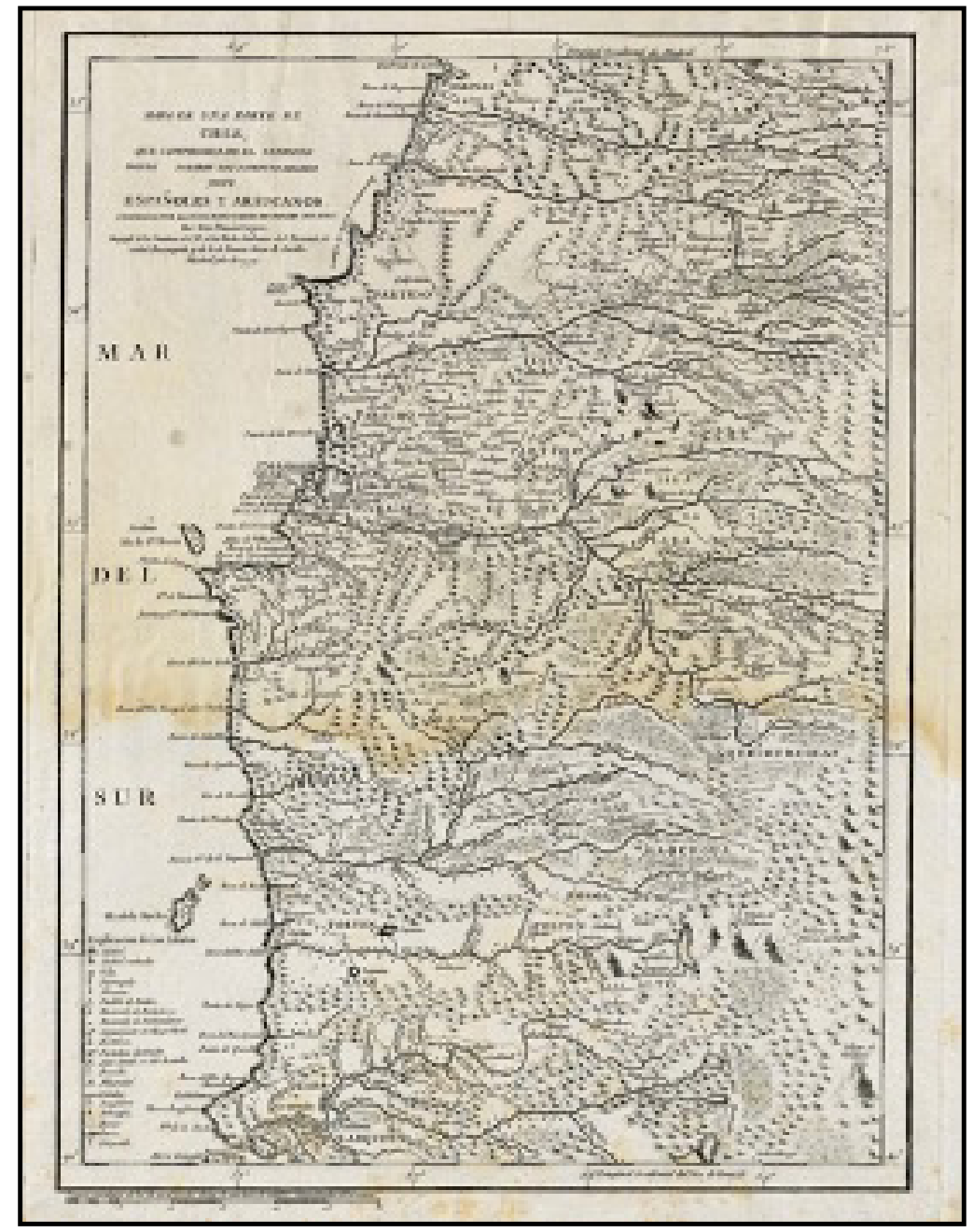

Figura 4. Cartografía del sur de Chile, siglo XVIII.

Tomás López, 1777. Actuales regiones del Maule a Los Ríos.

Original in the John Carter Brown Library at Brown University.

"Arique es el primer pueblo que se encuentra [...] pero las casas no están agrupadas alrededor de un centro común, sino desparramadas a los lados del camino. La iglesia pintada de rosado hace mui buen efecto en medio de los campos verdes", escribió Cox (1863, p. 110). La comitiva se aloja en casa de Francisco Lagisse, alemán que había establecido una de las fábricas de aguardiente de grano que se utilizaba como moneda de cambio por el ganado pehuenche. Cox cuenta que salieron para Huitri, "fundo perteneciente a don Atanasio Guarda", y describe las vueltas del Calle-Calle, en una de las cuales confluye el Quinchilca, donde "se encuentra la pequeña aldea del mismo nombre, formada de unas cuantas casas". La comparación entre la cartografía actual y la señalética rutera con la crónica confirma que la toponimia indígena está conservada. Si bien describe la iglesia, Cox no menciona la misión de Arique sobre el río Calle-Calle de la cual se desconoce el emplazamiento, pero que Ascasubi (1997) identifica y caracteriza en su informe de las Misiones Religiosas de Chile hacia 1789. Discutimos a la vera de la ruta las posibilidades, teniendo en cuenta que no quedaron vestigios porque fue construida en madera. Visitamos el cementerio donde se agrupan tumbas de mapuche y "espańoles", 
como los primeros seguían identificando a los huincas en 1863. Reconocemos las de Jacinto W. Agüero A. y Filomena Agüero, apellido de Ignacio, intendente de Valdivia durante la década de 1840, autor de las cartas recomendando a Cox ante los pehuenche (1863, pp. 107-109), aprovechando sus influencias desde joven cuando había intervenido a su favor en los enfrentamientos con los huilliche y tehuelche como capitán de indios amigos. En medio de las tumbas hay fragmentos de cerámica sin torno, que podría ser tanto prehispánica como colonial, evidencia de los usos sucesivos y la convivencia de las ocupaciones.

Cox señala Quinchilca en su mapa y aclara que la misión se encuentra donde el río de idéntico nombre se junta con el Calle-Calle, que se origina a su vez en el lago Lácar (Cox, 1863, p. 201). Menciona una carta que el cacique Huincahual, su principal anfitrión en Las Manzanas, le había enviado al juez por "un pleito entablado entre un Pehuenche i un chileno" (Cox, 1863, p. 263). El juzgado de Quinchilca, y a su frente Emilio Agüero Asenjo, sobrino del influyente Ignacio, continuarán oficiando como mediadores en conflictos entre mapuche y criollos de ambas bandas, que tuvieron por causa principal el ganado caballar, hasta entrada la ocupación argentina. Así lo muestra una carta de este juez a Saygüeque en 1880, reclamando los mismos principios de buena relación que invocaba Huincahual. ${ }^{8}$ Aquí importa la manera en que las redes sociopolíticas se tramaron con la presencia determinante de los mismos actores, parentelas, y los mismos nodos territoriales como Quinchilca mientras se configuraban las fronteras nacionales. Los Agüero y los mapuche criollos como los Cárdenas, que despertaron la atención de Cox, hicieron de nexo entre los manzaneros o pehuenche como Saygüeque, el intendente de Valdivia e incluso el presidente Aníbal Pinto, cuando buscaron apoyos en Chile durante la agresión argentina que rompió con 25 años de tratados entre las autoridades de Buenos Aires y los caciques. ${ }^{9}$

Nuestro viaje siguió con la visita a la misión franciscana de Quinchilca (1778) y su iglesia, restaurada por el obispado de Valdivia después del incendio de 1996. Nos recibe Roberto Correa, quien colaboró con el plan de reconstrucción. Esta persona, que es propietaria de una importante colección arqueológica, explica la importancia que tuvo Quinchilca como comuna hasta la caída de la plaza realista de Valdivia en 1820, cuando el gobierno patriota fundó Los Lagos como cabecera, ya que se facilitaba la comunicación fluvial, aunque Quinchilca continuó como misión. Durante los siglos XVIII y XIX las misiones franciscanas de Niebla, Arique, Quinchilca y Río Bueno cumplieron un rol doble de evangelización y avanzada territorial para expandir el radio de colonización. La topografía circundante ratifica que los emplazamientos como Quinchilca se ubicaron en zonas de movilidad, y terrazas elevadas que permitían el control visual, situadas en la confluencia de ríos y vías de circulación. Estas observaciones coinciden con las prospecciones arqueológicas, que evidencian una ocupación de los valles con un área cultivable potente. Quinchilca se hallaba en la bifurcación del camino, uno por el sureste hacia el lago Ranco y de allí a Llifén, el que siguió Cox, y otro noreste por Panguipulli hacia los boquetes de Hua-Hum y Carirriñe, que también exploraríamos. A diferencia de Valdivia, que era un nodo urbano, y de Cruces que era una fortificación, o del lago Ranco que estaba controlado por mapuche, Quinchilca se diferenció como nodo de transición, aunque tuviera

8 Emilio Agüero Asenjo, Juez de Subdelegación de Quinchilca No 1, 23 de marzo de 1880. Archivo General de la Nación (en adelante AGN) VII, legajo 723, f. 409.

9 Carta de Víctor Gutiérrez, Visitador de Escuelas, a Emilio Agüero, 31 de marzo de 1880. AGN VII, legajo 723, f. 411. En el Archivo Nacional de Chile (ANCh) hay informes sobre estas redes transcordilleranas por parte del juez de subdelegación de Quinchilca No 1, Emilio Agüero Asenjo. ANCh, Intendencia de Valdivia, vol. 45, Correspondencia de Juzgados de diversas subdelegaciones y distritos, $1876-1888$. 
una ocupación indígena bien asentada con la que debieron negociar los españoles para instalar la misión, más aún si se considera que era lo primero que destruían los mapuche cuando los acuerdos entraban en crisis (Guarda, 1953).

La Misión de Quinchilca, junto con la de Niebla, son las únicas que se construyeron en piedra (Urbina y Adán, 2012, 2014). Ello permite disponer de un registro como los muros en ruinas de las edificaciones antiguas, próximas a la iglesia restaurada. La infraestructura es un indicio de su importancia y, dada su ubicación estratégica, Quinchilca funcionó como centro de acopio de materiales, botijas de vidrio, chaquiras y carne seca. La fiesta de la Candelaria, que cada 2 de febrero repite su esplendor, es otro indicador de la centralidad de esta misión que conectaba el área de los llanos con la costa y los Andes, intensamente poblada, como se desprende de las descripciones de Cox.

Respecto de la colección arqueológica del señor Correa, son cerca de 50 piezas de cerámica provenientes de dos cementerios de Malihue, sector de mapuche-huilliche disputado por varios encomenderos. La cerámica es estilo Valdivia, rojo sobre blanco, además de un plato estilo Tringlo. Uno de los cementerios del que proviene la mayor parte tendría piezas de cerámica Pitrén, más temprana que Valdivia. Este cementerio tiene una definición multicomponente, cerámica del alfarero temprano, Valdivia, y Tringlo (Adán, Mera, Bahamondes y Donoso, 2007; Adán y Mera, 2011; Adán y Urbina, 2012; Adán, Mera, Munita y Alvarado, 2016). Esta colección está siendo estudiada para inscribirla en el Consejo de Monumentos Nacionales, ser donada y constituir un museo local. La mitad de las piezas de uno de estos cementerios está en posesión de otra persona. Tienen dibujos completamente distintos del estilo Valdivia, curvas, rombos y reticulado similares a los motivos del arte rupestre en Puelmapu, otro indicador de conectividad en el plano de la cultura material.

El 23 de diciembre de 2015 retomamos el viaje por la costa del lago Ranco, avizorando la abertura de Llifén. Margarita Alvarado lee en voz alta un fragmento de Cox que coincide con el paisaje visto desde la carretera:

Don F. Acharan dueño de la hacienda de Dollingo vive allí, ocupándose de la crianza de animales. Todos los Huilliches que trajinan por ese lugar, conocen muí bien esta casa, en donde nunca se les rehusa la chicha i el alojamiento [...]. Salimos de Dollingo por una pampa rodeada de bosques [...] seguimos subiendo i bajando por las pequeñas ramificaciones que se desprenden de los dos grandes cordones laterales que forman ese largo valle que concluye en el boquete [...]. Todo el camino que es como de doce quilómetros hasta Futronhue, asi se llama una pampita a orillas del lago de Ranco, en donde viven algunos indios, es de pampas alternadas con bosques (Cox, 1863, pp. 111-112).

Próximos a ese punto, que se presenta como una última frontera de colonización, Marcelo Godoy señala atento a la descripción: "Aquí está un cordón y aquí el otro cordón, por aquí al medio pasó Cox" (Figura 5). La próxima posta del viajero será el rancho de Antonio Panguilef en la Mariquina, un "pariente de los caciques Pehuenches i que en ese momento se hallaba en el otro lado de la cordillera”. Junto al lago Ranco, Cox se alojó en otra casa del paraje Huequecura, acceso al portezuelo cerca de la pampa de Llifén que da nombre al boquete. Importa destacar, una vez más, cómo registra el cronista la continuidad de las redes comerciales y defensivas que integraban parientes con territorialidad y circulación en ambas bandas. 


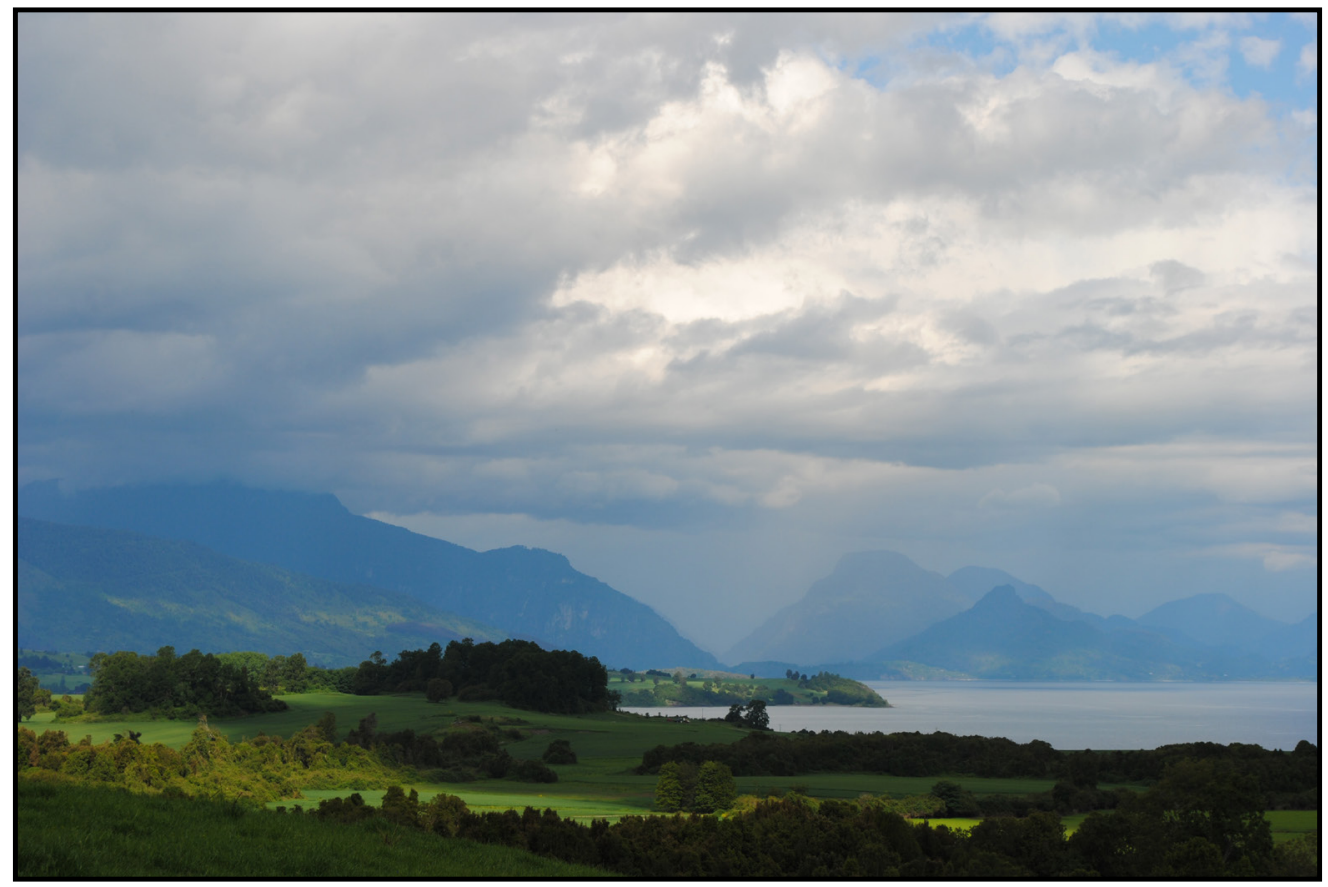

Figura 5. Acceso a boquete de Lilpela desde Coique, lago Ranco.

Entrada al boquete Lilpela por Llifén desde Coique, lago Ranco, comuna de Futrono, provincia de Valdivia, Chile. Fotografía: Marcelo Godoy.

Pasamos frente a las islas pequeñas en el centro del lago Ranco que Cox vio a la distancia (1863, pp. 111-112), "algunas de ellas habitadas por indios" y con campos de trigo. Exploramos el sitio del fortín Coique, construido por los mapuche, supuestamente en el siglo XVI para controlar el boquete de Llifén, cuyos vestigios Cox no menciona. Actualmente se alza un condominio con viviendas modernas. Ya en el antiguo recinto del fortín, rodeado por la foresta, Simón Urbina cuenta que al prospectar no hallaron mucho material arqueológico, y desde el borde de la terraza explica el detalle arquitectónico del foso cavado hace más de 400 años. Agrega que no lo descubrió el equipo de arqueología de la Universidad Austral, sino "los profesores del lugar, todos lo conocen, toda la población local por tradición oral".

Nos hospedamos en un complejo turístico administrado por la comunidad mapuche de Illahuapi Bajo, en la península homónima emplazada en el sureste del lago Ranco. Al día siguiente retomamos la ruta para Arquilhue, donde hay restos de otro fortín antiguo que tampoco fue advertido por el explorador, ya encima del portezuelo. Cox sí menciona el topónimo y describe que "las pampas son mucho mayores", que los "ranchos de vaqueros se ven de cuando en cuando" y que "en todos los potreros se ocupan de hacer quesos" (p. 113). Las pampas de Arquilhue y las cercanías del lago Maihue ocuparán un lugar destacado en el fresco fronterizo, ya que funcionaban como punto de encuentro, intercambio, preparativos y organización de cargamentos (Figura 6). 


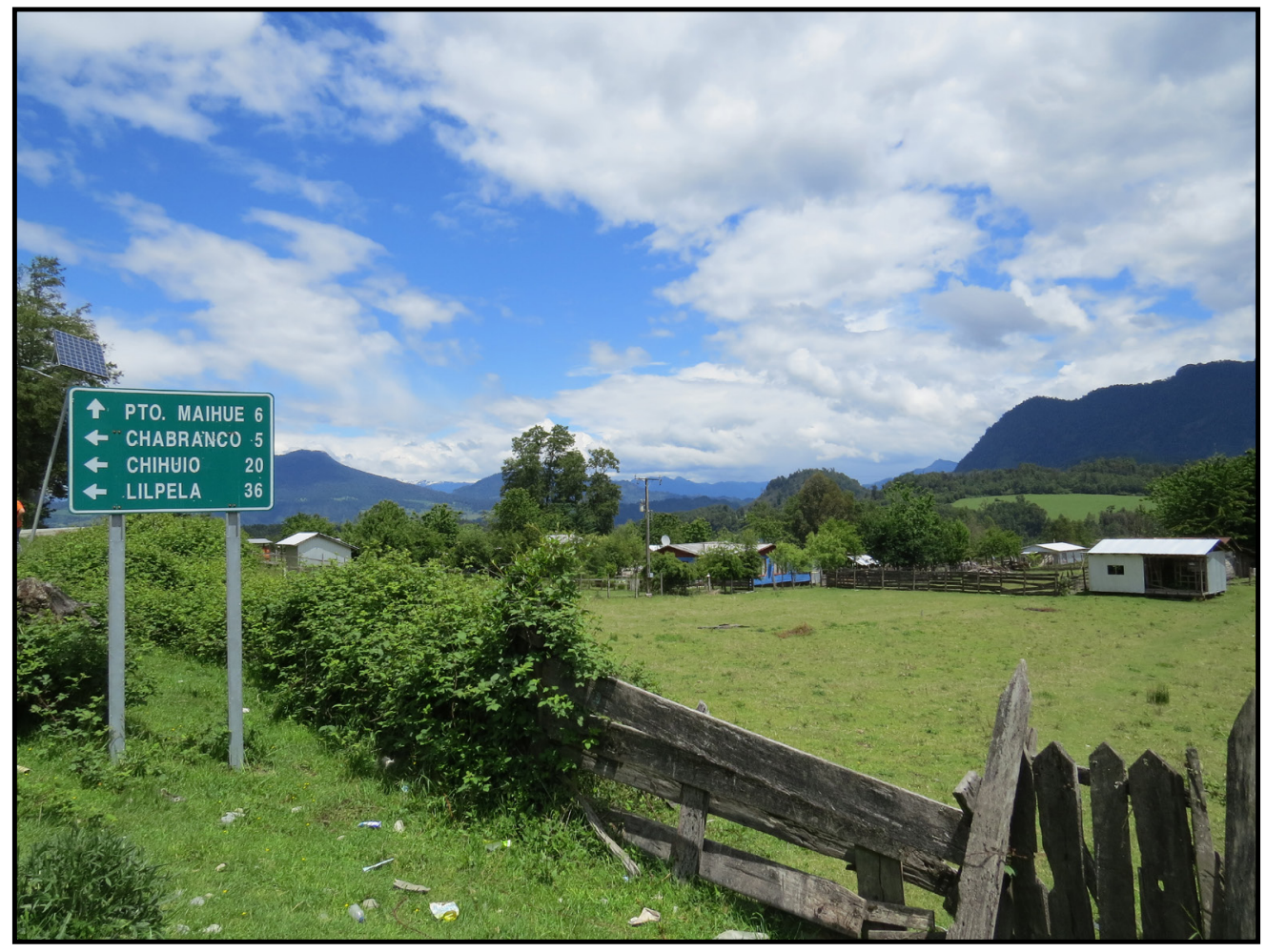

Figura 6. Imagen del sector Maihue, cruce de caminos al paso Lilpela. $\mathrm{Al}$ este (fondo) se encuentra el lago Maihue y hacia el norte el paso cordillerano. Fotografía: Julio Vezub.

Antes de Maihue, "Futronhue" significa 'lugar de humaredas', lo que sería indicativo de las técnicas para comunicarse, avisar, pedir permiso y convocar a distancia, como lo sugirió Luis Carreño Palma en un comentario personal. En el "potrero de don Manuel Florín” en Arquilhue se reunirán los principales actores de la red trasandina en un ámbito que Cox (1863) menciona como "la última estación en este lado de la cordillera":

En la casa encontré algunos indios Pehuenches sentados bajo una ramada, bebiendo en compañía de mi grande amigo Juan Negron [...] Entre estos indios se hallaban unos dos, que eran hermanos: Pedro i Manuel Montesinos, apellido español que habían adoptado i vivian en la otra banda, en los toldos de Huitraillan, cacique Pehuenche de las orillas del Chimehuin. También estaba con ellos Pedro Cárdenas, (Motoco), hermano de mi mozo, i otro joven José Bravo, lenguaraz y secretario del cacique (Cox, 1863, pp. 114-116).

Cox se refiere a José del Carmen Marques Bravo (SIC), escribiente valdiviano que ofició como secretario de los hermanos Llanquitruz y Chingoleo, su primo Saygüeque, y su tío Utraillan entre 1856 y 1868, fechas extremas de la correspondencia de su autoría que se conserva en el AGN en Buenos Aires. Mediador paradigmático entre Valdivia, los mapuche, tehuelche, y la plaza argentina en el Atlántico, Marques Bravo fue un operador leal a dicho linaje de caciques, aunque tuvo compromisos con todas las partes, ya que se desempeńaba como "baqueano" de la guarnición de Carmen de Patagones en los toldos de Valcheta en el sudoeste de Río Negro, 
allí donde la comandancia bonaerense había situado a los "indios amigos" de Llanquitruz y sus sucesores (Vezub, 2009, p. 75). Sobre "otro joven chileno" apellidado Labrín, que con "su querida" se hallaban cautivos en los toldos de Paillacan, y acababan de ser liberados, Cox manifiesta que "[e]s difícil espresar la satisfacción que experimentaba esa pareja al verse libre i en medio de jente civilizada. Habían permanecido un año entre los salvajes" (Cox, 1863, p. 114). Es llamativo, por contraste, dado que estaban a muy pocos kilómetros o días de marcha de su lugar de cautiverio, y el entorno social era prácticamente el mismo como para diferenciar entre civilización y salvajismo. Aunque el carpintero de Cox, Mancilla, quien también había sido liberado por los caciques después de construir una casa sin esperar el regreso del jefe, ratifica la oposición, afirmando que "[...] ni por todo el oro ni el aguardiente del mundo consentiría en ponerse otra vez en las manos de la canalla de la otra banda" (Cox, 1863, p. 116).

Mientras se bebía y se conversaba en Arquilhue se reforzaban vínculos estrechos, frecuentes, y con protagonistas repetidos. Varios asumen particularidades de los desplazados de origen, y han participado en las más variadas experiencias. Son personas que aparentan estar fuera de lugar, lo que les facilita adaptarse a la novedad cultural y al desafío de otras lenguas, identidades y territorios. Que esta última frontera estuviera fuera de control o vigilancia aparece en la crónica bajo estado de sospecha. A lo sumo se trataba de la "puerta trasera" para acceder al mundo indígena, como la caracterizó Navarro Floria (2012, p. XIV), pero desde la perspectiva chilena. En Maihue la partida es alcanzada por el "inspector" y juez de la comarca de Arique, Bonifacio Vázquez, quien hace comparecer "en defensa de las costumbres cristianas" a Matías González, un viejo chileno "lenguaraz" que había vivido mucho tiempo con los pehuenche, para impedir que venda su hija a uno de ellos, además de persiguir una "chola" criada del juez, que se fugaba al otro lado con un hombre (Cox, 1863, pp. 121-122). Aunque sea infructuosa o esporádicamente, y cediendo, tan profundo como hasta allí alcanzaba el brazo de la autoridad estatal.

Cuando emprendemos la ruta "por la larga pampa" (Cox, 1863, p. 117) hasta Maihue y el río Pillanleufú que baja desde un volcán, son notorios los cambios por desforestación y ganadería. "Esto debió ser pura vegetación", acota Margarita Alvarado, sugiriendo que el concepto de "pampa" hace alusión a un terreno llano, no necesariamente despejado. "Seguro había una huella grande porque es más plano para transitar", acota Marcelo Godoy en el punto en que termina el asfalto y la vegetación se hace más apretada, próximos a donde vivía el cacique Cayu-antú en 1863, cuya casa oficiaba como "cuartel general" de Juan Negrón. Junto al fortín de Arquilhue identificamos en la carta del Instituto Geográfico Militar de Chile (IGM) los ríos y los cerros que menciona Cox. Se advierte la explanada central del fuerte, que desde un punto de vista funcional debió estar acondicionado para los corrales que eran necesarios para el tránsito ganadero (Figura 7).

Simón Urbina aclara que se trata de un fuerte y no de un fortín, porque su planta es rectangular y tiene dos baluartes de los que se conservan montículos. Está flanqueado por el río Blanco hacia el este. A diferencia del fortín de Coique, tiene una inversión en la excavación de los fosos más grande, ya que no cuenta con una posición topográfica estratégica, y es abordable por todos lados. Probablemente, el recinto abierto haya servido para el ganado. Las excavaciones dieron cuenta de fragmentos de material cerámico mapuche doméstico, algunos platos de mayólica, piezas de hierro y lascas de obsidiana: "una mezcla en el fondo bicomponente, mapuche, hispana, colonial", precisa Simón, quien agrega que las excavaciones fueron acotadas, quedando trabajo pendiente. El equipo no ha realizado fechados, pero dada la tipología de los materiales, el fuerte podría ser del siglo XVI al XVIII: "por la arquitectura, por la planta, pensamos que es español a diferencia de Coique, aunque esto no quiere decir que no haya sido mapuche en su origen". 


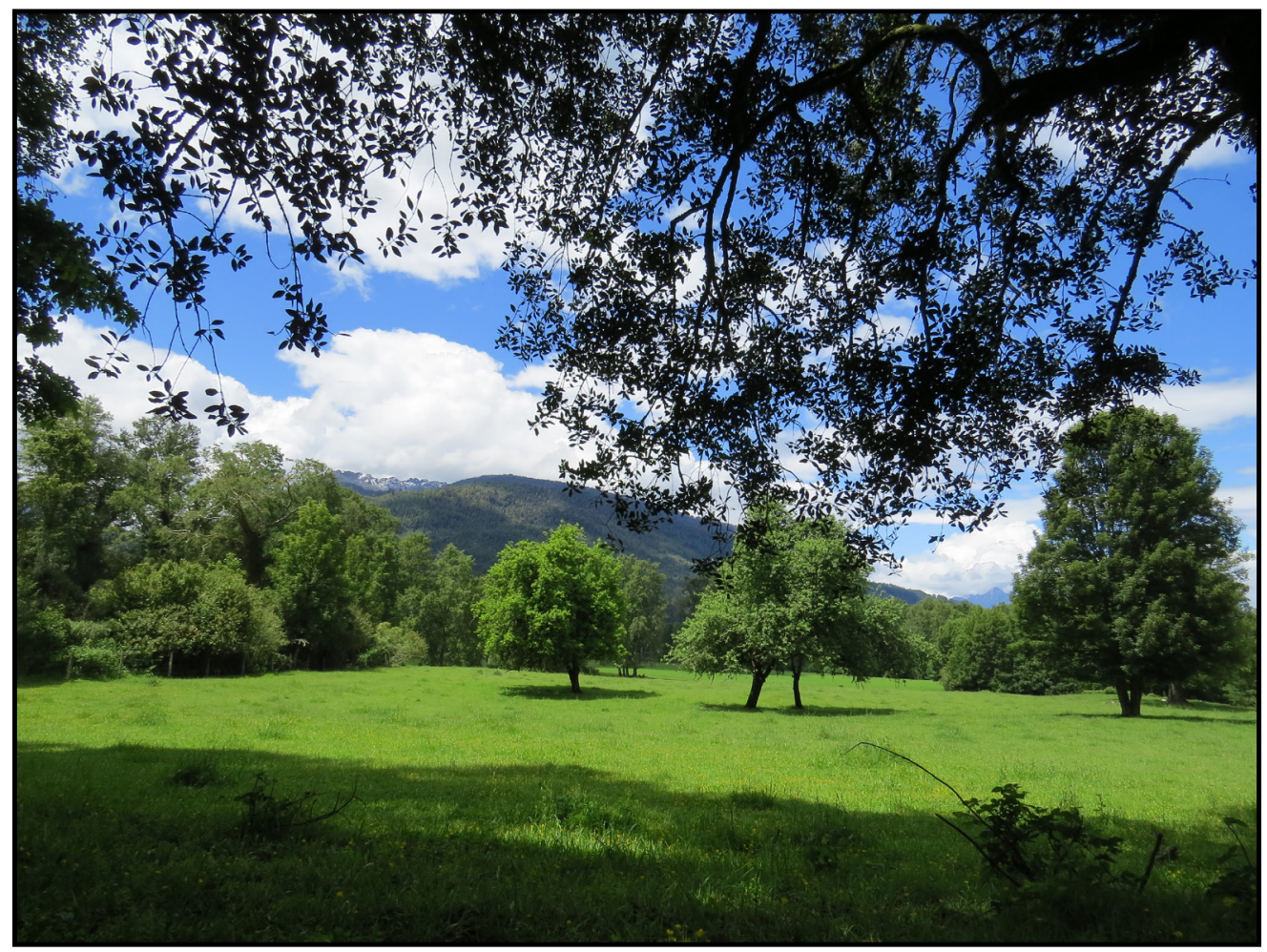

Figura 7. Emplazamiento del Fortín Hispano de Arquilhue.

Arquilhue corresponde al valle encajonado que avanza en dirección S-N rumbo a paso Lilpela.

Fotografía: Julio Vezub.

Allí estaba Cox al momento del cruce: "La caravana esta vez se componía, además de mi persona, de Lenglier, los dos Cárdenas, José Bravo que llevaba aguardiente a los toldos de Huitraillan [...] Caminábamos al paso con intención de ir a pasar la noche a Chihuihue, distante solamente doce kilómetros" (Cox, 1863, p. 122). Cox mide la temperatura de las aguas termales que le enseña Motoco Cárdenas apartándose apenas a la derecha del sendero, "a poca distancia en la cordillera que faldeábamos". Pasamos por este punto, ahora con alojamientos y explotaciones turísticas donde está la vertiente de agua a $24^{\circ}$. Inmediatamente, una tranquera atraviesa el camino, impidiéndonos seguir. Se trata del fundo San Juan de Chihuio, de 5600 ha. Un letrero indica que es propiedad privada, y que las llaves están en poder del cuidador. Este nos atenderá junto a su esposa y, por lo menos en la demografía, si se hace abstracción de la tranquera, la situación no parece diferir de la que observó Cox en 1863: "Aunque en este lugar hai una casita, en la que viven un indio i su mujer, nosotros dormimos al aire. Era preciso, desde ese momento, decir adios al confortable de la vida civilizada”.

Chihuio (Chihaihue) será el lugar de pasaje al territorio pehuenche transcordillerano, un punto de no retorno en el relato de Cox, quien describe que su comitiva ingresa en las ramificaciones directas del boquete, "[...] subidas i bajadas, algunas de ellas bastante pendientes i mui húmedas a causa de lo espeso del bosque que no deja penetrar el sol: unas veces faldeábamos el cordón derecho, otras el izquierdo, separados solo por la quebrada angosta, por donde corre el torrentoso rio Follil que atravesamos cinco veces" (Cox, 1863, p. 123). "Folil chalfallal", folil es como raíz, traduce Margarita Alvarado. Chihuio es el punto que no podremos trasponer, a 
la inversa del cronista se trata del retorno, más allá del kilómetro que amablemente nos permitieron caminar el cuidador y su esposa, hacia otro puesto del fundo que está a cargo del hijo.

Impedidos de continuar, confrontamos la carta 1: 50.000 "Baños de Chihuio" del IGM con el mapa de Cox y los hitos a simple vista que seńalan el cruce. La extendemos sobre el capot de uno de los vehículos: "Aquí son puros nevados, si pasás por aquí es como un laberinto sin salida, aquí no podés pasar, acá tampoco, o sea, y si venís por acá tenés que subir esta quebrada que es infernal". "Por aquí va Cox, por la cota de los $970 \mathrm{msnm}$, sobre el curso del Queñi, que es el desagüe del lago del mismo nombre del otro lado, y el boquete coincide con la seńalización de la carta, el "HITO VIII-22 PASO DE IPELA". Más allá de los nevados, Cox seguirá por Hua-hum, hasta el lago Lácar (Figura 8).

A la derecha del camino y el alambrado de púas se distingue una traza más antigua del sendero, que ingresa en el bosque. Señalamos en la carta del IGM el punto más al este que alcanzamos en la pampa Sobarzo, justo donde todavía se alza la casa de madera que algunos lugareños refieren como lugar de descanso de Pablo Neruda antes de pasar clandestinamente al exilio en 1949 durante la presidencia de Gabriel González Videla. Por entonces, Lilpela se conocía como el "Paso de los Contrabandistas". ¿Habrá leído el poeta la crónica de Cox? ¿Sabría que guiado por sus baqueanos repetía exactamente el mismo paso a casi 90 ańos? Lo que sí sabemos es que el boquete está inhabilitado, y que su acceso queda dentro de un fundo privado. Seguramente, Cox cabalgó por esta pampa hacia el hito. En la ladera izquierda, por detrás de las instalaciones

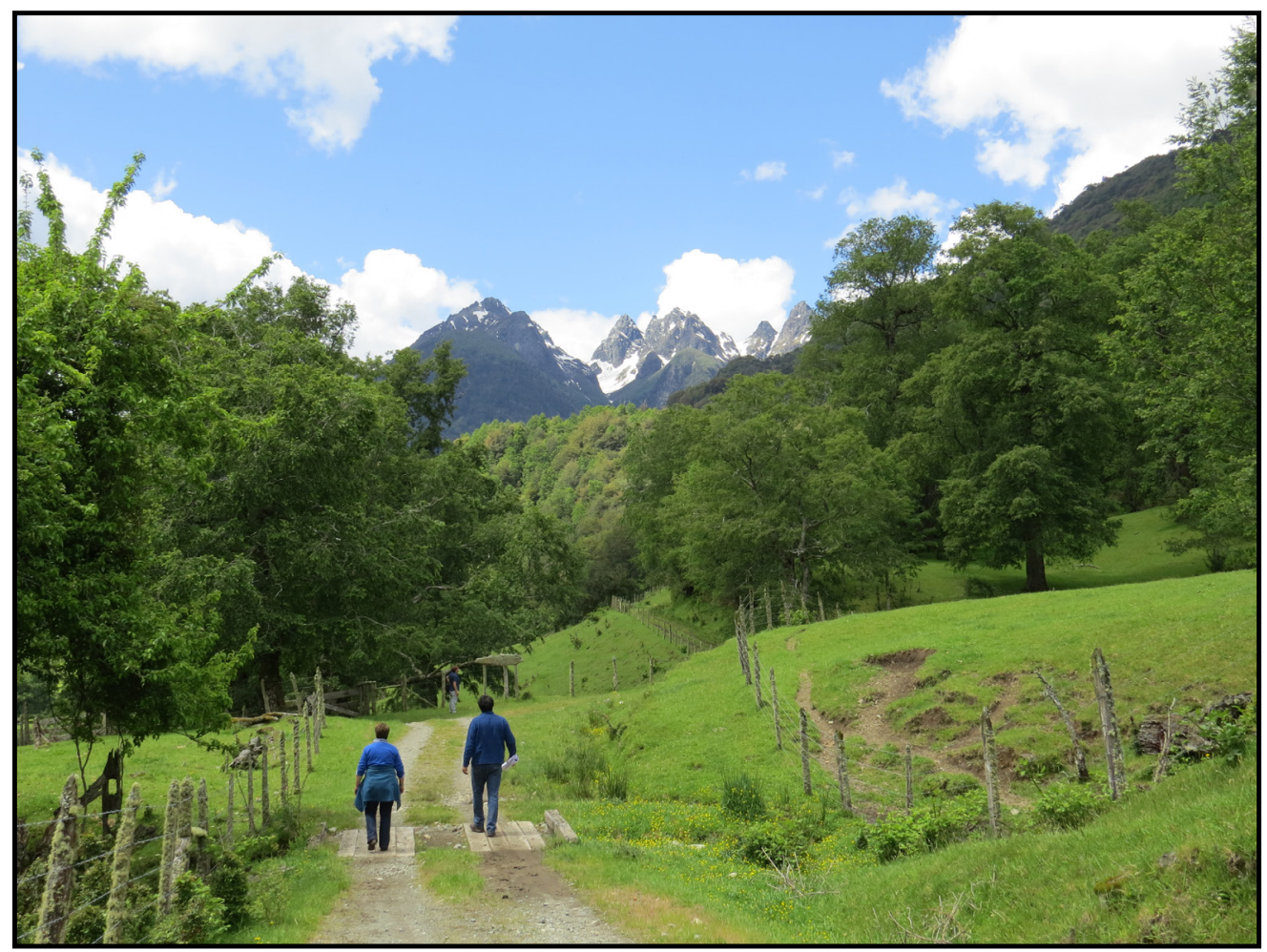

Figura 8. Parte del equipo de investigación en el paso Lilpela. Senda que conduce al boquete cordillerano emplazado entre los picos de los Andes. Fotografía: Julio Vezub. 
y la casa por donde transitó Neruda, se extiende la selva valdiviana. Marcelo Godoy concluye que probablemente el paisaje sea muy parecido al bosque que conoció Cox, y que las partes más altas de la ruta estarán en las mismas condiciones con un sendero mucho más cerrado, ya que el tramo que transitamos está muy afectado por la explotación maderera.

Delante del último punto que alcanzamos (Figura 9), trasponiendo la próxima loma, cinco horas de caminata nos separan del Puelmapu, ahora Argentina, y lo que no llegamos a ver: la cuesta de Lilpela que "es el verdadero paso", el sendero "cortado a pico", según Cox que expresa que "no hai palabras para dar una débil idea de lo que es esta infernal ascensión" (Cox, 1863, pp. 123-124). Ya del otro lado, encontrará la meseta de Inihualhue, donde la comitiva cumplió el rito de pasaje de dar tres vueltas en un pie alrededor de un círculo de $3 \mathrm{~m}$, asegurando el éxito del viaje, las tumbas de dos pehuenche muertos durante una nevada con ofrendas de flores y verduras, el lago Queñi, y el balseo en Hua-Hum donde se estrechan los lagos Nonthué y Lácar, y donde encontró indígenas pehuenche a la espera de prestar el servicio de balsa, y cobrarlo.

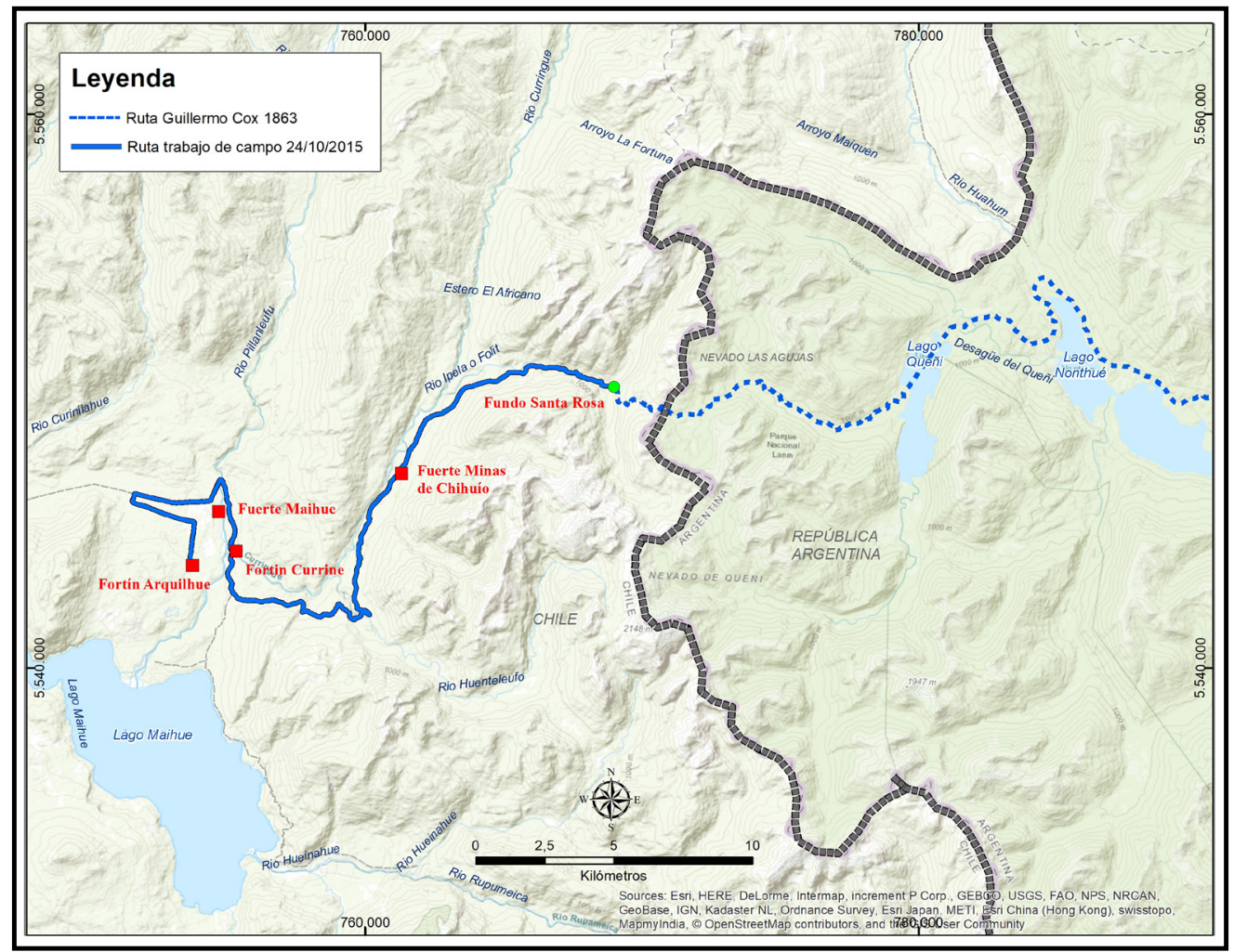

Figura 9. Cartografía con detalle del paso Lilpela seguido por Cox.

Seguimiento de la ruta de Cox, en el paso Lilpela, comuna de Futrono, provincia de Valdivia. La línea entera realizada con registro GPS, la línea punteada representa el tramo sin transitar. Fuente: Elaboración propia. 


\section{El futuro pasado de caminos y archivos que se bifurcan}

Las bifurcaciones de senderos y archivos nos llevaron por un laberinto de tiempos históricos que se superponen entre sí (Koselleck, 1993, p. 14), y que alguna vez convergen (Borges, 1994, p. 478). El fundo San Juan de Chihuio, último hito del viaje de Cox inmediato al límite binacional hasta donde nos fue permitido pasar, debió quedar abarcado en el Complejo Forestal y Maderero Panguipulli, empresa del Área de Propiedad Social del gobierno de Salvador Allende (1970-1973) donde trabajaron cerca de 3600 personas. A medida que se fueron agotando los bosques de los valles, la explotación forestal comenzó a penetrar la cordillera: "Al día de hoy se describen bajadas de balsa en el río Calcurrupe, el desagüe del Maihue hasta el lago Ranco que se embarcaban en el tren cordillerano", explica Marcelo Godoy. Margarita Alvarado aclara que la gran explotación extractiva fue a partir de la década de 1960, y luego la expropiación durante la presidencia de Salvador Allende: "[...] ahí viene una cosa más razonada, y después viene Ponce Lerou, ingeniero forestal y yerno de Augusto Pinochet, que privatizó y destruyó todo, no solo en términos productivos sino en términos de la gente".

Una vez interrumpido el rastro de Cox, bifurcamos caminos y continuamos por idéntica morfología de paisaje, atentos a las marcas que dejaron los sucesos del siglo XX, conectando futuro y pasado con presente. El 25 de noviembre de 2015 pernoctamos en Panguipulli y, de regreso, encontramos a la vera de la carretera el memorial de los obreros forestales ejecutados en Chihuio cuando el golpe de Estado en Chile, en 1973. "Sin justicia sin olvido", reza el crucifijo de madera. La lápida fechada en Currińe en 1998 detalla los nombres de los 18 asesinados. Una placa familiar proclama: "PAPITO: SOLO TU NOMBRE ESTARÁ ESCRITO HOY AQUÍ ALGÚN DÍA TU CUERPO HALLAREMOS. TUS HIJOS - CHIHUIO. VAL. 5-4-2003”. Y otra, también en letras capitales, declara "AUNQUE LOS PASOS TOQUEN MIL AÑOS ESTE SITIO, NO BORRARÁN LA SANGRE DE LOS QUE AQUÍ CAYERON”. El memorial introduce una cuña en esta historia por capas, o palimpsesto, como el "territorio" según la definición de Corboz (2004), un manuscrito antiguo sobre el cual se acumulan marcas y escrituras que no borran los trazos del pasado ni los secretos que guardaba el bosque desde antes de Cox.

Estamos en Neltume en lo que fue el corazón del Complejo Forestal. La dictadura desató una represión salvaje con dos generaciones de muertos, la primera en 1973 y la segunda, la de los hijos que generaron los movimientos de resistencia en los años ochenta. Este fue el caso de los 11 jóvenes del Movimiento de Izquierda Revolucionaria (MIR), que después de ingresar clandestinamente desde la Argentina fueron asesinados luego de ser descubiertos en plena faena de construcción de "tatús", o refugios subterráneos de inspiración vietnamita en pleno invierno de 1981. Al regresar a Valdivia asistiríamos a la inauguración de El complejo, instalación con documentación de archivo y video sobre la historia del asesinato de estos miristas, autoría de Claudia del Fierro, que se montó en el Museo de Arte Contemporáneo de la Universidad Austral, cuyo edificio albergó la barraca de la cervecería Anwandter desde mediados del siglo XIX hasta su destrucción por el terremoto de 1960.

En la localidad de Neltume, a orillas del río Fuy sobre el camino al paso internacional de Hua-Hum, se alza otro memorial (Figura 10), dedicado en este caso a todas las víctimas de la dictadura de Pinochet que eran militantes, funcionarios y trabajadores del Complejo. Las placas listan a los fusilados en Valdivia, los 18 ejecutados en Chihuio, y los "otros 26 caídos del Complejo en 1973". Se leen nombres mapuche, como Tracanao Pincheira, apellido de los hermanos realistas que lideraron la montonera mestiza que libró la "Guerra a Muerte" en la Araucanía durante las revoluciones de independencia. 


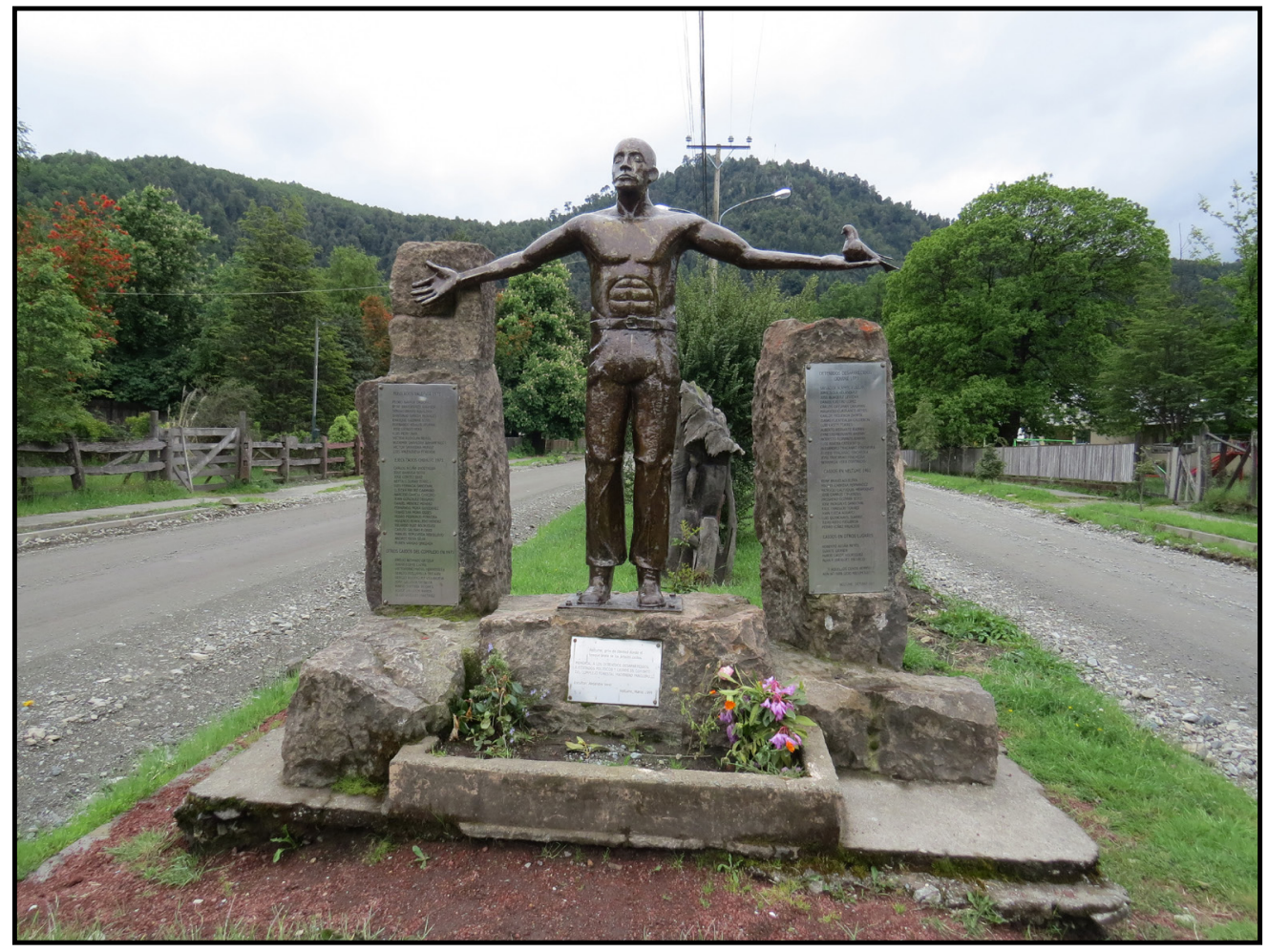

Figura 10. Memorial de Neltume, comuna de Panguipulli, Los Ríos, Chile.

Memorial inaugurado el 14 de octubre de 2001 en homenaje a las 70 víctimas de la represión de la dictadura militar. Fotografía: Julio Vezub.

Frente al memorial se alza una casa que era la oficina administrativa, allí donde Salvador Allende pasó la noche jugando ajedrez con los trabajadores durante su visita en 1972 (Osvaldo Alvarado, representante gubernamental en el Consejo de Administración, com. pers.), y que actualmente es la sede del Museo y Centro Cultural Memoria Neltume. Manifiesto de la cultura forestal y carpintera, la leyenda del mural expresa: "Usted entenderá en milímetros yo entiendo en pulgadas". "Neltume: Grito de libertad donde el bosque brota en los árboles caídos". Próximo, como parte de las nuevas formas de territorialización que dejaron la dictadura y la privatización, se encuentra Huilo Huilo, un parque y resort de lujo para turismo y convenciones empresariales, ofrecido como "la reserva biológica del sur del mundo".

Seguimos por un camino secundario de Neltume a Liquiñe, que conecta con dos pasos internacionales que, a diferencia de Llifén, sí están habilitados, Hua-Hum y Mamüil Malal, aunque este acceso es poco transitado y solamente lo recorren lugareños. Costea el lago Neltume y pasa por una cancha de nguillatun donde se sumergen ofrendas. Cruzamos el fundo La Frontera camino a un cuarto paso, Carirriñe o Liquiñe. Se trata del boquete que atravesó Pascual Cońa con la comitiva de lonkos que se entrevistó con el presidente Julio Argentino Roca en Buenos Aires después de visitar a la gente cautiva de Saygüeque y Ñancucheo en 1885 (Bello, 2011, p. 157).

A la derecha del camino de ripio se distinguen las marcas de la antigua huella, debajo de una lomada. Marcelo Godoy detalla que al norte de este punto hasta los Nevados de Sollipulli 
contabilizó doce pasos cordilleranos en campañas anteriores, y que solamente los de Icalma, Pino Hachado y Mamüil Malal están formalmente habilitados. Dos años después, durante la travesía que haríamos para confirmar datos, se sumaría Carirriñe entre las comunicaciones permitidas entre ambas naciones, aunque se clausura durante el invierno por las nevazones.

Nos detuvimos en la "Avanzada Carirriñe (T.F.)" de Carabineros que todavía estaba en construcción en 2015. Un portón metálico cerraba el paso de la estrecha senda de arena volcánica que corre por el túnel natural que arman las copas de las lengas (Nothofagus pumilio) para ir al otro lado, los lagos Paimún y Epulafquen, que desaguan en el Huechulafquen, Neuquén. El guardia de seguridad civil nos muestra un cerro al otro lado del cerco, "no es muy alto", dice, mientras señala un sendero que apenas se distingue a media altura, donde pasan contrabandistas y prófugos por las noches, y todo aquel que no hace migraciones ni aduana. Marcelo Godoy apunta que probablemente fuera la traza de la antigua rastrillada de caballos. No resulta difícil imaginar pequeños arreos y partidas de comerciantes de aguardiente, yendo y viniendo en tiempos de Cox por lo profundo del bosque. "Litrán", la piedra colgante que refiere Cońa (1995, p. 293), fue dinamitada por el Ejército de Chile para obstruir el paso e impedir el ataque de su par argentino cuando estuvieron a punto de ir a la guerra en 1978 (Álvaro Bello, com. pers.). De regreso optamos por otro camino que también nos devolvió al límite. El topónimo es "Paimún", igual que el río que corre paralelo, pero no tiene contacto con la cuenca del lago argentino que está a $11 \mathrm{~km}$ según el GPS. Hay un fundo homónimo y otro lago de nombre idéntico, pero en Chile. Lagos, ríos y áreas repiten la denominación sin importar el limite, como evidencia de que todos estos accidentes configuraban una unidad de paisaje y lugar antes del trazado fronterizo. Si se pudiera explorar, probablemente, se descubriría otra senda antigua que también lleve al Puelmapu por este punto.

El 26 de noviembre la pesquisa continuó en Río Bueno, donde además del archivo parroquial visitamos el fuerte, refundado en 1793 al igual que la misión franciscana San Pablo Apóstol, que se había instalado en 1778 dando origen al caserío. Simón Urbina cuenta la historia del fuerte reconstruido en 1982, que sigue un patrón cuadrangular clásico con cuatro baluartes y una vista estratégica desde la barranca del río: "Estos muros explican el archivo que consultaremos y ese archivo explica estos muros, en el sentido de una tecnología de registro y control social, o la posibilidad de llevar el inventario de los nacimientos, matrimonios y defunciones por parte de los misioneros en relación a la autoridad política y militar". Simón se pregunta por la dualidad del fuerte asociado a la misión: custodiar el camino que se estaba abriendo, y cuidar la misión de los huilliche que eran reacios a la entrada de los españoles, especialmente los del sur del río Bueno. El binomio fuerte-misión no se dio en todos los casos; no se dio en Niebla, tampoco en Quinchilca, supuestamente, y no estuvo en Arique. Los arqueólogos concluyen que esta configuración binaria se produjo en este poblado porque era un área tensa, sin que fuera suficiente con la visita periódica de un capitán de indios amigos para defender la misión. Aunque esta necesidad debió ser recíproca, ya que la misión posibilitó a las autoridades coloniales del fuerte un tipo de mediación imposible de sostener solamente con armas. Las excavaciones que el equipo realizó en la barranca entre los baluartes y fosos registraron alfarería mapuche, loza europea, cantidades de vidrio y clavos forjados de sección cuadrada con dataciones de fines del siglo XVIII y, en mayor cantidad, de principios del XIX.

Primero exploramos el archivo del Museo Municipal Arturo Möller Sandrock de Río Bueno, que aportó datos sobre el comercio entre ganaderos mapuche y chilenos, que quedó asentado en el libro de registro de transacciones de ganado que se realizaban a fines del siglo XIX, la existencia de un tipo de animal denominado "buey cordillerano", y al menos la compraventa de 
un caballo "argentino". Después consultamos la documentación del Archivo Parroquial de Río Bueno (Figura 11), que permitió constatar las hipótesis iniciales sobre la dinámica poblacional y las relaciones entre hispanocriollos y mapuche que se construyeron en torno a los religiosos, ya que estos registros parroquiales dieron cuenta de la ocupación colonial, influencias e interpenetración del territorio, al menos desde el último cuarto del siglo XVIII.

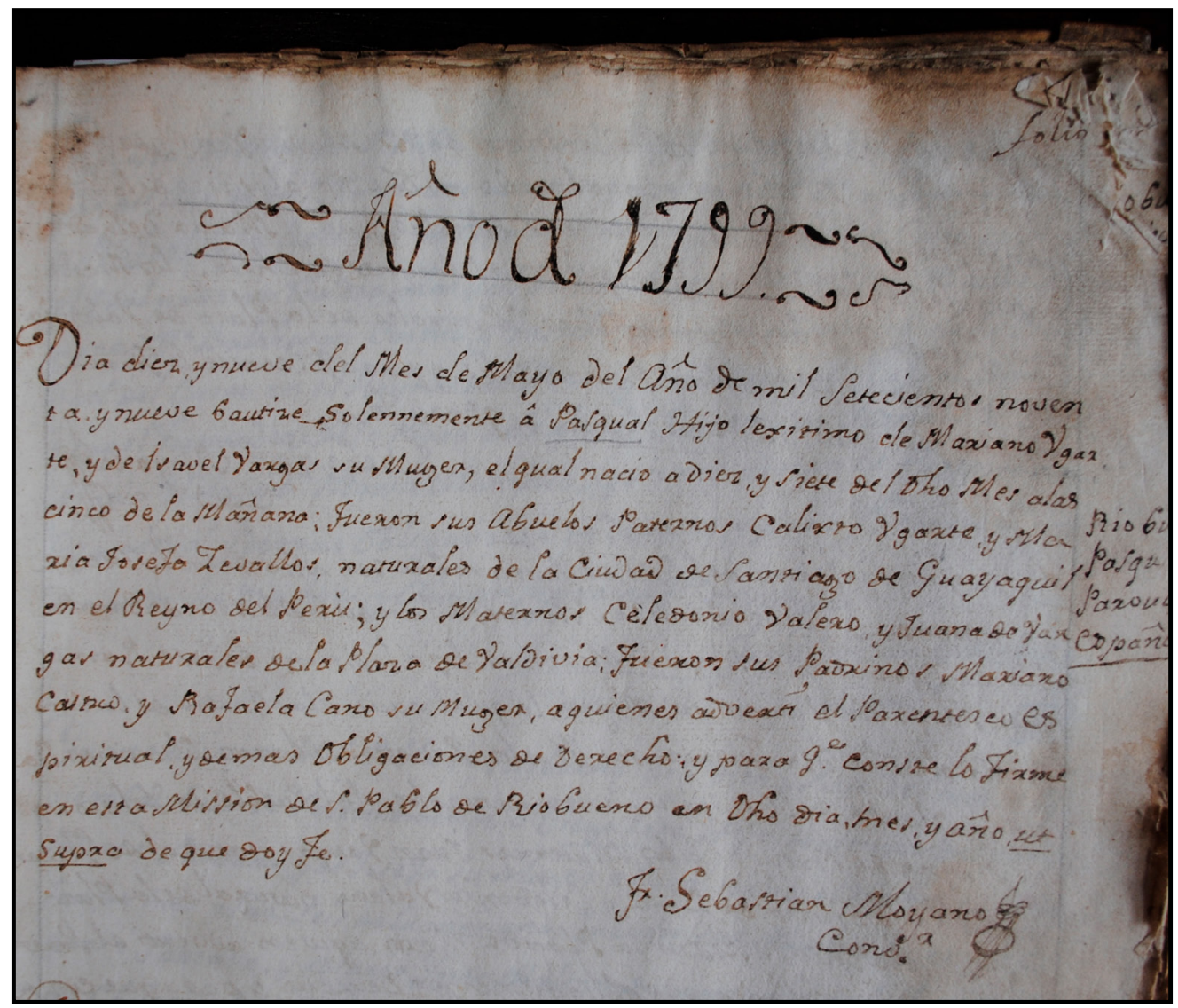

Figura 11. Libro de bautismo del Archivo Parroquial de Río Bueno, provincia de Ranco.

Los archivos misionales dan cuenta de bautismos y matrimonios, tanto entre espańoles como mapuche, a contar de su refundación en 1793.

En el Archivo Parroquial de San Pablo en Río Bueno según año y período, colonial o republicano avanzado, los asientos clasifican a los bautizados en distintos libros. Por ejemplo, "espańoles y mestizos" para el "Año Dominus 1799", mezclando ambas categorías, lo que podría ser indicador de emparentamiento, e "indígenas" en 1860-1871, ya en época de Cox. Se trata de registros muy completos que alternan el latín con el italiano de varios de los misioneros, y el español. Los asientos de bautismos y matrimonios cubren series continuadas desde 1793, fecha de refundación de la misión, y merecen estudios específicos para cuantificar la población, ya que dispone de listados de referencia con la identificación de un número muy importante de personas de los siglos XVIII y XIX en la región de influencia. El conjunto es un muestrario de la densidad de la trama demográfica mapuche, o mestiza, si se rescata la categoría que proviene de las fuentes, que se extendía desde Valdivia hacia parajes que se definen con precisión en la 
mayoría de los casos, y hacia otras localizaciones inciertas como "las montañas", ${ }^{10}$ que darían cuenta del territorio más allá del dominio efectivo, y la autonomía de las redes sociales que articulaban los caminos hacia el Puelmapu.

Los asentamientos tempranos muestran la varianza de tipificaciones de castas y el cosmopolitismo colonial: hay datos sobre personas de Cuzco y Guayaquil del Reino del Perú, "Natural de la Sierra de Lima”, Talca, junto con portugueses, provenientes de "Castilla la Vieja”, individuos como "Juan Bautista Vaxa natural de Francia”, y también de Santiago, Chiloé, Valdivia, "indios gentiles", "infieles", "india natural de Pilmayquen", o un nacido en "Toledo (casado con india de esta reducción)", etcétera. Revisamos asientos:

Dia veinte y quatro de Junio del Año de mil ochocientos y tres bautice solemnemente en esta Mision de Riobueno a Juana Hija Legitima de Antonio Díaz el Manchego, Europeo, y de María Mahuis india natural de Riobueno: Fueron sus padrinos Ermenegildo Oliba y Barthola aquienes advertí el Parentesco espiritual y demas obligaciones de derecho (...) Fr. Sebastián Moyano.

En el caso de los progenitores mixtos se trata de hombres de origen europeo, o criollo, unidos con mujeres indígenas. Sin embargo, no figuran matrimonios de hombres indígenas con mujeres criollas, así como tampoco registros de uniones de esta índole entre los bautizados, tampoco en el libro de casamientos "Para Españoles":

Dia quince de Noviembre de mil ochocientos veinte y cinco casé y velé en la Iglesia de San Pablo Apostol de Riobueno a Josep Maria Pobeda natural de Riobueno hijo legitimo del difunto Benito Pobeda y Maria Catalan con Juana Lican, natural de Chinchinco, hija de Payllacheu y Llancúnash infieles: fueron testigos Dn Josef Rubio y Felipa Prieto, de que doy fe. Fr. Antonio Hernán Calzada.

Los registros proveen información histórica de distinta calidad como las vicisitudes del ataque y destrucción de la fundación original en 1792, y los acuerdos inmediatos con Ambrosio O’Higgins:

Con el motivo de haver venido a Riobueno el 15 de Marzo del año 1793 en busca de los vasos Sagrados, y el Cacique Dn. Juan Gueypul, que aun estaba [ilegible] expresamente a los Españoles, no obstante el perdon que se le concedio a nombre del Rey por el Sr Capitán Gral Dn Ambrosio Ohijins supe por dho Cacique, y por sus Indios que me recivieron llorando, y pidiendo perdon de esos atentados, todo lo que executaron en esta Misión, cuando se alzaron, y el modo con que mataron a mi Compañero Fr. Antonio Cunco hijo de la Prov. de Cataluña, hallandome ausente yo...

Dia veinte y tres de Septiembre el año de mil setecientos noventa y dos a las nueve de la noche dieron estos Indios de Riobueno contra la Misión en ataque y en su jurisdicion mataron cinco Españoles, cautibaron dos mugeres con sus hijos, y

10 Archivo Parroquial de Río Bueno. Bautismos de españoles y mestizos. Año D 1799, y Bautismos de Indigenas IV, 1860-1871, f. 103: "En esta Iglesia de S. Pablo el dia doce de Noviembre de mil ochocientos sesenta y cinco, bautizé solemnemente a Carolina de un mes hija legítima de Feliz Nahuelpan y de Ma Manuela Guinthinagh de las montańas. Fue madrina Rufina Vera, de que doy fe. Fr. Pedro de Saircola”. 
al P. Dn. Sr. Antonio Cunco lo sorprendieron entre la cocina y Casa Misional, haciendole una lanzada al brazo [...] sedientos de sangre española (Libro Universal 1, Bautismos, Casamientos y Entierros 1793-1816, Misión de San Pablo de Riobueno).

En el libro de bautismos de indígenas correspondiente a 1860-1871, la década durante la cual Cox transitó el territorio de influencia de esta misión, aparecen apellidos de varios de sus contactos o interlocutores, como Juan Fermín Montesino en carácter de padrino (Foja 35, asiento diciembre 1861), y muchos de los kümpeñ o 'nombres de buena familia' en mapuzungun (De Augusta, 2002), que portaban los anfitriones del explorador, y los lonkos y "grandes hombres" de las tolderías de Las Manzanas como Nancucheu. También figuran madrinas mapuche, y nombres y apellidos españoles, aunque sus portadores fueran de territorio indígena como el "padrino de agua y óleo" José Hilario Uribe, "natural de Guillimappo", según la anotación de fray Gaudencio del 22 de diciembre de 1861.

El repaso de este libro de bautismos indígenas abunda en laku (nombre impuesto del abuelo o el tío) (Jiménez, 2002), y kümpeñ, que son prestigiosos en el presente a ambos lados del límite. Estos se leen en otros documentos contemporáneos a la crónica de Cox como la correspondencia entre caciques y autoridades de Chile y Argentina (Vezub, 2009): Anthilef, Huinca, Huala (Huincahual fue el principal anfitrión del viajero en el Caleufú), Nahuelpan, etcétera. Abunda el linaje "Hueque" (la oveja o cordero de los sacrificios), y nombres propios muy parecidos a Saygüeque ("Chihueque" en los libros ), o similares a los de otra gente de su familia que conoció Cox como Utraillán ("Huantrellán”). Se repiten nombres de profundidad histórica en Puelmapu como "Chamel” (Chanel o Chanyl era el abuelo de Llanquitruz y Saygüeque), y el registro llamativo de bautismos que también son topónimos como "Limay", precisamente el río donde naufragó Cox en el punto más lejano que conoció al este de los Andes, y "Maihue", el lugar de encuentro donde reunió los animales y provisiones antes de cruzar.

El 27 de noviembre de 2015 finalizaríamos el trabajo de terreno, entrevistas y relevamiento visitando el Archivo del Obispado de Valdivia. Nos recibió el padre Gonzalo Espina Peruyero, administrador apostólico de la diócesis, y consultamos la documentación, sumamente dañada, carbonizada y húmeda. Fue rescatada de un incendio que afectó la ciudad en 1909, y es muy valiosa ya que contiene información mayormente inédita, sin que conste que los historiadores hayan hecho uso intensivo de ese material, a excepción del religioso Gabriel Guarda. Es mucho más abundante que el archivo de Río Bueno, y al abarcar una diócesis, incluye registros de distintas misiones y parroquias, como los bautismos, confirmaciones, casamientos y entierros de Quinchilca desde 1868 hasta 1939, correspondencia entre las misiones y las autoridades eclesiásticas, y libros copiadores, cartas y oficios, anotaciones fiscales, etcétera, que fueron ordenados por misión, vicaría o parroquia.

Surge de las partidas de matrimonios que durante diferentes épocas la Iglesia otorgó permisos para que los viudos mapuche se casaran con sus cuñadas, que eran madres de sus hijos, indultando a los contrayentes al justificar la "cópula licita" (SIC), tal como se lee en las "Varias partidas de Matrimonios, i dispensas de varias épocas”.

En el Libro de Oficios de la Parroquia de Nuestra Señora del Rosario y Vicaria Foránea de Valdivia, se observa el patrón de los documentos tardocoloniales consultados en Río Bueno. Se repiten los "bautismos de indios" de Calle-Calle, pampas de Arique y Antilhue, y otros parajes en la ruta de Cox, los apellidos españoles de padrinos y madrinas que este menciona, y que vimos 
en las cruces de los cementerios, como Agüero, Montesinos y Olavarría -el anciano que había acompañado a fray Menéndez en las expediciones a Puelmapu de la década de 1790-, y también padrinos mapuche como Ayeñamcu, aunque en menor medida. Abundan los bautismos "Artículo Mortis" de recién fallecidos, "hijos de padres infieles", y se nota la proliferación de relaciones de servidumbre que se refuerzan con los padrinazgos de militares, que a su vez son propietarios de chacras:

Dia veinte y ocho de Octubre de mil ochocientos y diez, baptizé solemnemente a Simona, la que ya tenia tres días, hija legítima de Manuel Cayupag y de Gregoria havitantes en la Chacara del Capitan Gabriel Guerrero quien fue Padrino, y su hija Petronila a quien advertí las obligaciones contraidas de que doy fe. Fr. Martín Fernandez.

Padrinos y madrinas a menudo eran matrimonio. Componían la red laica que se entrejía con la misional y la militar con clientelas y servidumbres mapuche. Por ejemplo, el Capitán de Amigos Guerrero era esposo de María Olavarría, madrina espańola, según un bautismo asentado por el fraile Juan Ferretjans en 1806. La utilización de alias era frecuente entre los varones, aludiendo al rol militar y mostrando la inserción en redes, como anotó el fraile comisionado de misiones el 18 de diciembre de 1807:

"[...] baptizé solemnemente a Josefa Parvula de un dia nacida hija natural de Antonio, infiel (alias el Miliciano) y de Mercedes Viuda de Simon Millamanque, los dos de Antilue, y para que conste lo firmo, y fue Madrina Josefa India de esta Sra Rosa Miranda, Cocinera de la Misión, a quien advertí el Parentesco espiritual y demas obligaciones de que doy fé".

Igual que en el archivo parroquial de Río Bueno, aparecen en los registros de Valdivia los nombres relevantes al otro lado de los Andes como Curripilun, y Bernardo Namuncura, bautizado el 20 de septiembre de 1808 y recién nacido en Cunco, homónimo del que sería escribano de su tío Manuel Namuncura, hijo de Juan Calfucura, y a su tiempo, cacique él mismo. Para indicar dónde habitaban las personas, se anotaron topónimos como "Chimeuyùm", muy similar a Chimehuin, el destino final de los dos viajes de Cox, y otros que estaban en el camino como "Fúthonue" (Futrono) y Ranco, tan profundo hacia el este como llegaba el radio de influencia de la misión de Quinchilca en 1799.

Como indicador de la demografía, solamente si se consideran las personas que recibían sacramentos, la visita a la Misión de la Purísima Concepción de Arique (fundada en 1776) que realizó en 1807 el "Comisionado Prefecto de todos los dependientes del Colegio de Chillan, fray Francisco Xavier de Alday, computó un total de 905 bautismos (834 párvulos y 71 adultos) desde la fundación. Para Quinchilca el 23 de Febrero de 1799, un comisionado prefecto antecesor, fray Francisco Pérez, había anotado 520 párvulos y 122 adultos bautizados desde la creación de esta misión en 1778. Quiere decir, un promedio anual de 25 o 26 bautismos de infantes en 20 años. Mientras que los matrimonios celebrados desde esa fecha hasta 1817 ascienden a 249 según el libro que se conserva en el archivo del Obispado.

Cox recogió memorias de la Misión de Nahuel Huapi (Cox, 1863, pp. 85 y 145) sobre la cual los misioneros dejaron relaciones desde 1670 hasta su destrucción en 1720 . Por su parte, Francisco P. Moreno oyó decir en 1875 que Inacayal guardaba la campana, y que los mapuche 
manzaneros vincularían la historia de la misión con la búsqueda de la ciudad de los Césares (Moreno, 1897, pp. 255-256). Esta misión, sostenida por expediciones que anticiparon la ruta trasandina de Cox, antecedió 80 años los registros consultados. Si se asocian la impronta que dejó la Misión de Nahuel Huapi en los relatos del último tercio del siglo XIX al este de los Andes y la cantidad de sacramentos impartidos desde Valdivia montańas adentro que verificamos en los archivos, se resalta la penetración evangelizadora del mundo fronterizo que recorrió Cox por senderos de colonización ya previamente transitados (Pinto, 1988).

\section{Conclusiones}

A partir del camino y la crónica de Cox como fuentes principales se confrontaron las transformaciones de un paisaje que está profundamente alterado, y que muestra sus conexiones regionales rotas a partir del trazado del límite entre los Estados. A pesar de los cambios demográficos desde tiempos coloniales que seńalan las investigaciones antecedentes, se observan continuidades en el uso de vías, especialmente las que conectan a Valdivia y las que remontan la cordillera hacia el Puelmapu.

Durante el viaje de 2015 se entrevistaron personas que están muy próximas al “otro lado”, pero que no lo conocen y lo idealizan, porque operativa y funcionalmente les queda muy lejos, y con obstáculos. Aunque esto no sea así en todos los casos, ya que también se oyen relatos de caminadores, contrabandistas y fugitivos que utilizan boquetes que hoy no están legalmente habilitados.

La observación arqueológica, antropológica y etnohistórica permitió ir analíticamente del siglo XIX al XVIII en el marco del proyecto original sobre arqueología histórica, y regresar del período colonial a los siglos XX y XXI, identificando los cambios socioambientales. Los documentos de archivo ratificaron la importancia del eje social Valdivia - Carmen de Patagones para los mapuche e hispanocriollos desde la fundación de esta última en 1779. La metodología de tratamiento de fuentes permite sostener las dos hipótesis que se plantearon sobre los niveles avanzados de colonización socioterritorial que describió Cox en 1863, y la importante densidad demográfica a lo largo de la ruta por el curso del Calle-Calle hacia el lago Ranco y las montañas. El cotejo de la crónica con la tipología documental que se detalló, las marcas del paisaje, y la evidencia arqueológica, reitera que se trataba de un espacio social que había sido previamente transitado por religiosos, militares, hacendados y comerciantes que superponían roles, y que propiciaron el fin de la autonomía poblacional y territorial a favor de la imposición del Estado. La alteridad radical que Cox pintó en su relato puede resultar disonante con la realidad de la penetración colonial hacia 1863, y hace pensar que podría tratarse de discurso de propaganda. Sin embargo, el tramo que recorrió desde Futrono hasta Maihue y Arquilhue, y los protagonistas de la red trasandina que se reunían en esa "última estación" antes del cruce de la cordillera, son la medida del contraste político y cultural donde el Estado solo arrimaba emisarios o mediadores ambivalentes.

Por más que el paisaje y las configuraciones soberanas hayan cambiado con la instalación de límites nacionales, los hitos y lugares se mantienen, conservan toponimia e indicios de generaciones pasadas. Por ejemplo, están presentes en los apellidos en las cruces de los cementerios, y en los registros parroquiales. Se pudo confirmar que Cox fue un observador atento de la geografía y la sociología de este segmento regional mapuche, y los eslabonamientos sociales que le permitieron pasar de un lugar a otro, ida y vuelta dos veces en el verano de 1862-1863. 
Conforme a la metodología interdisciplinar con que se abordó el trabajo de campo, el contraste es congruente entre las observaciones del camino, la historia social y el ambiente descritos por Cox, y su crónica de 1863. A su vez, las anotaciones de Viaje en las rejiones septentrionales de la Patagonia son coherentes con la evolución del panorama territorial y poblacional que emerge de los archivos parroquiales tardocoloniales que se consultaron en Río Bueno y Valdivia. Siguiendo a Bello (2011), lo que hilvanaba la discontinuidad segmental del territorio mapuche eran los caminos, y eso fue lo que se reconstruyó al andar la ruta de Cox.

El andar por los caminos fue develando otras conexiones secretas que se mantienen entre $\mathrm{Ngu-}$ llumapu y Puelmapu pese al paso del tiempo. Entre estas la historia del médico chileno-belga Pedro Cardyn (2017), presente en el vernissage de la exhibición El complejo, quien sobrevivió a la masacre de los jóvenes miristas, cuya esposa se apellida Chocorí, el nombre poco frecuente del padre de Saygüeque, que constituye un enigma de la etnología y la lingüística patagónicas. La noche de ajedrez de Allende en Neltume, o el cruce clandestino de Neruda, que repetía el itinerario y los peligros vividos por Cox, una aventura mejor recuperada por las historias que en San Martín de los Andes se cuentan a turistas. Relatos que informan en pleno siglo XXI que sobre el paso de Hua-Hum estaba instalado el aserradero de los descendientes de Isbrand van Dorsser en 1949. Se trataba de los mismos pioneros holandeses cuya casa de madera incendiada fue reconstruida junto al destacamento de la Gendarmería Nacional Argentina como "lugar de memoria".

Como corolario del registro de terreno, llama la atención que esa "casita" de los holandeses, como epítome de la colonización moderna, sea el único hito histórico que se señala a la vera del camino de Cox, justo allí donde caravaneros mapuche, "españoles" chilenos y otros sujetos irreductibles a la clasificación transportaban comunicaciones, ganado, aguardiente, mercancías, y facilitaban la ida y vuelta de personas. Se recuerda a Neruda, los miristas y la represión todavía fresca ocurrida en el Complejo Forestal y Maderero Panguipulli, pero no queda memoria de Cox. Del lado argentino sucede otro tanto, también quedan ecos del paso del poeta, sobreviven los topónimos que el viajero registró en 1863, incluso lof como Trompul tienen su territorio al pie del cerro que apuntó en su carta. Pero predomina la épica estatal de los pioneros, descontextualizada, reconstruyendo la vivienda allí donde pasaban chasques y arreos que conectaban ambos lados del Wallmapu.

En una vertiente cultural o emprendedora, los resultados que se presentan en este artículo podrían tener implicancias en materia de desarrollos turísticos e integración. En una vertiente política, retoma la agenda sin resolver de la autonomía territorial mapuche.

Al volver en 2017 en la dirección contraria para ratificar los datos del trabajo de terreno, yendo de San Martín de los Andes hacia Valdivia por el paso de Hua-Hum, compartimos la barcaza por el lago Pirehueico con una nutrida delegación de funcionarios de las alcaldías de la región de Los Ríos que regresaban de reunirse con sus pares argentinos. Se puede leer esta historia de los mapuche y los viajes de Cox como fundamento histórico para los proyectos de corredor biocéanico, también de patrimonialización turística, que actualizarían las visiones de lord Parish sobre la libre navegación de los ríos. Simultánea y conflictivamente con ese mandato futurista de la globalización, toda operación política que facilite la integración regional debería hacer justicia a la memoria histórica de la autonomía del País Mapuche del siglo XIX, advirtiendo su vigencia y los problemas sin saldar que ha dejado la imposición de los Estados nacionales. 
Como tarea para un próximo terreno, faltó solamente atravesar la verdadera "tierra de nadie", un segmento de pocos kilómetros cuesta arriba y abajo, el lugar de la ofrenda de los caravaneros que celebraban el rito del traspaso que atestiguó Cox, allí donde ahora se interpone un fundo privado al que ni siquiera accede el Ejército de Chile, y el límite nacional en el tramo más abrupto de los ventisqueros.

\section{Referencias citadas}

Adán, L., Mera, R., Bahamondes, F. y Donoso, S. (2007). Síntesis arqueológica de la cuenca del río Valdivia: proposiciones a partir del estudio de sitios alfareros prehispánicos e históricos. Revista Austral de Ciencias Sociales, 12, 5-29. doi:10.4206/rev.austral.cienc.soc.2007.n12-01

Adán, L. y Mera, R. (2011). Variabilidad Interna en el Alfarero Temprano del Centro-Sur de Chile: El Complejo Pitrén en el Valle Central del Cautín y el Sector Lacustre Andino. Chungara. Revista de Antropología Chilena, 43(1), 3-23.

Adán, L., Mera, R., Munita, D. y Alvarado, M. (2016). Análisis de la cerámica de Tradición Indígena de la jurisdicción de Valdivia: Estilos Valdivia, Tringlo y decorados con incrustaciones. En Mena, F. (Ed.). Arqueología de la Patagonia. De Mar a Mar (pp. 313-323). Coyhaique: Ediciones CIEP.

Adán, L. y Urbina, S. (2012). Elementos Para La Caracterización Arqueológica de las Relaciones Interculturales en la Ciudad de Valdivia entre los Siglos XVI y XVII. En Actas XIX Congreso de Arqueología, Simposio Estrategias y Procesos de Dominación y Resistencia. Arica, Chile.

Adán, L., Urbina, S. y Alvarado, M. (2017). Asentamientos humanos en torno a los humedales de la ciudad de Valdivia en tiempos prehispánicos e históricos coloniales. Chungara. Revista de Antropología Chilena, 49(3), 359-377.

Alioto, S. (2011). Indios y ganado en la frontera. La ruta del río Negro (1750-1830). Rosario: Prohistoria.

Ascasubi, M. (1997 [1789]). Informe cronológico de las misiones del reino de Chile hasta 1789. Cuadernos del Archivo Franciscano, 44.

Bechis, M. (2008). Piezas de etnohistoria del sur sudamericano. Madrid: Consejo Superior de Investigaciones Científicas.

Bellelli, C., Scheinsohn, V., Podestá, M. (2008). Arqueología de pasos cordilleranos: un caso de estudio en Patagonia norte durante el Holoceno Tardío. Boletín del Museo Chileno de Arte Precolombino, 13(2), 37-55. http://dx.doi.org/10.4067/S0718-68942008000200003

Bello, A. (2011). Nampülkafe. El viaje de los mapuches de la Araucanía a las pampas argentinas. Territorio, politica y cultura en los siglos XIX y XX. Temuco: Universidad Católica de Temuco.

Bengoa, J. (2008). Historia de los antiguos mapuches del sur: desde ante de la llegada de los Españoles hasta las paces de Quilin: siglos XVI y XVII. Santiago: Catalonia.

Berón, M., Di Biase, A., Musaubach, G. y Páez, F. (2017). Enclaves y espacios internodales en la dinámica de poblaciones en el wall-mapu. Aportes desde la arqueología pampeana. Estudios Atacameños. Arqueología y Antropologia Surandinas, 56, 253-272. 
Bocco, G., Cinti, A., Vezub, J., Sánchez-Carnero, N. y Chávez, M. (2019). Lugar y sentido de lugar en un camino de la costa atlántica patagónica, 1950-1970. Región y sociedad, 31, e1127. doi.org/10.22198/ rys2019/31/1127

Borges, J. (1994). El jardín de senderos que se bifurcan. En Obras Completas, I (pp. 472-480). Buenos Aires: Emecé Editores.

Boschín, M. T. (1975). Aproximación hacia la Reconstrucción Etnohistórica de la cuenca del río Limay y zonas adyacentes. Siglos XVII a XIX (Prov. del Neuquén). Tesis de Licenciatura. Facultad de Filosofía y Letras, Universidad de Buenos Aires, Buenos Aires, Argentina.

Boschín, M. T. (2009). Tierra de Hechiceros. Arte indigena de Patagonia septentrional Argentina. Salamanca: Editorial Universidad de Salamanca.

Bustos, J. (1993). Indios y blancos, sal y ganado más allá de la frontera. Patagones 1820-1830. Anuario IEHS, $8,27-45$

Camus, P. y Solari, M. (2008). La invención de la selva austral. Bosques y tierras despejadas en la cuenca del río Valdivia (siglos XVI-XIX). Revista de Geografía Norte Grande, 40, 5-22.

Cardyn, P. (2017). Sangre de Baguales. Epopeyas mapuches y obreras en tiempos del Complejo Maderero Panguipulli. Un efecto mariposa inconcluso. Santiago: LOM Ediciones.

Carreño Palma, L. (2005). El Alcohol de grano de Valdivia en Araucanía y las Pampas. Universum (Talca), 20(2), 172-181. https://dx.doi.org/10.4067/S0718-23762005000200009

Casamiquela, R. (1965). Rectificaciones y ratificaciones. Hacia una interpretación definitiva del panorama etnológico de la Patagonia y área septentrional adyacente. Bahía Blanca: Cuadernos del Sur, Instituto de Humanidades, Universidad Nacional del Sur.

Chávez, M., Vezub. J., Cinti, A. y Bocco, G. (2021). De la costa al interior: caminos, paisajes y redes trashumantes en el noreste de la Patagonia, Desacatos, 65. En prensa.

Coña, P. (1995 [1930]). Testimonio de un cacique mapuche. Santiago: Pehuén.

Corboz, A. (2004). El territorio como palimpsesto. En Ramos, Á. (Ed.). Lo urbano en 20 autores contemporáneos (pp. 25-34). Barcelona: Universitat Politécnica de Catalunya.

Cox, G. (1863). Viaje en las rejiones septentrionales de la Patagonia 1862-1863. Santiago: Imprenta Nacional.

De Augusta, F. J. (2002 [1907]). ¿Cómo se llaman los araucanos? Bahía Blanca: Centro de Documentación Patagónica, Universidad Nacional del Sur.

Del Fierro, C. (2015). El Complejo, Santiago: edición de autora.

Delrio, W., Guińazú, S., Bianchi, M., Bechis F., Savatier, Y., Arias, P. y Cañuqueo, L. (2018). Cartografías y construcciones de espacios fronterizos en Norpatagonia (fines del siglo XIX). Tefros, 16(2), 6-50.

Escalada F. (1949). El complejo Tehuelche. Estudios de Etnografía Patagónica. Buenos Aires: Instituto Superior de Estudios Patagónicos.

Foerster, R. y Vezub, J. (2011). Malón, ración y nación en las pampas: el factor Juan Manuel de Rosas (18201880). Historia, $44(2), 259-286$. 
Fonck, F. (Ed.) (1896). Libro de los diarios de Fray Francisco Menéndez. Valparaíso: Carlos F. Niemeyer.

Fonk, F. y Hess, F. (1857). Informe de los señores Francisco Fonk i Fernando Hess sobre la espedicion a Nahuelhuapi. Anales de la Universidad de Chile. Tomo 15. Serie 1. doi:10.5354/0717-8883.2010.2218

García, C. (2009). Cazadores recolectores en el área lacustre de la vertiente occidental andina (39 $\mathrm{S})$ : cronología, contextos y procesos. En Salemme, M., Santiago, F., Álvarez, M., Piana, E., Manzur, E. y Mansur, E. (Comps.). Actas VII Jornadas de Arqueología de la Patagonia. Una mirada desde el último confin (II, pp. 1011-1022). Ushuaia: Utopías.

Gardiner, A. (1841). A Visit to the Indians on the Frontiers of Chili. London: Seeley \& Burnside.

Godoy, M. (2014). Las rutas del Sollipulli hacia el Puel Mapu. Revista Austral de Ciencias Sociales, 27, 45-69.

González Díaz, G. (2017). Villarrica, Primera Ciudad Lacustre. Villarrica: Municipalidad de Villarrica.

Goñi, R. (1986-1987). Arqueología de sitios tardíos en el valle del río Malleo, Provincia de Neuquén. Relaciones de la Sociedad Argentina de Antropología, 17(1), 37-66.

Guarda, G. (1953). Historia de Valdivia. Valdivia: Municipalidad de Valdivia.

Guarda, G. (1980). Conjuntos urbanos históricos arquitectónicos. Valdivia, s. XVIII-XIX, Santiago: Nueva Universidad.

Guarda, G. (1990). Flandes indiano. Las fortificaciones del Reino de Chile 1541 - 1826. Santiago: Ediciones Universidad Católica.

Guarda, G. (2001). Nueva historia de Valdivia. Santiago: Ediciones Universidad Católica.

Guarda, G. y Moreno, J. R. (2010). Monumenta cartographica valdiviensae: Territorio y Defensa 1551-1820. Santiago: Corporación Amigos del Patrimonio Cultural de Chile.

Hadjuk, A. y Cúneo, E. (1997-1998). Rescate Arqueológico en San Martín de Los Andes (Departamento Laacar, Provincia del Neuquén) y algunas reflexiones acerca de la cerámica con decoración valdiviana. Relaciones de la Sociedad Argentina de Antropologia, XXII-XXIII, 319-341.

Harrington, T. (1946). Contribución al estudio del indio Gününa Küne. Revista del Museo de La Plata, Sección Antropología, II, 237-275.

Jiménez, J. (2002). Matrilinealidad versus patrilinealidad. La obra de Félix José de Augusta y la polémica acerca de la filiación entre los Reche Mapuche. Bahía Blanca: Centro de Documentación Patagónica, Universidad Nacional del Sur.

Koselleck, R. (1993). Futuro pasado. Para una semántica de los tiempos históricos. Barcelona: Paidós.

Mariño de Lobera, P. (2003). Crónica del reino de Chile. Biblioteca Virtual Universal / Facilitado por la Biblioteca Virtual Miguel de Cervantes. Argentina: Editorial del cardo. https://www.biblioteca.org.ar/ libros/89677.pdf

Melo, W., Jiménez, J. y Alioto, S. (2016). La ruta del cacique Llampilanguen (1804): la reconstrucción geográfica de un camino histórico. Boletín Geográfico, 38, 131-148. http://revele.uncoma.edu.ar/htdoc/ revele/index.php/geografia/article/view/1368/1412

Mera, R., Lucero, V., Vásquez, L., Harcha, L., Reyes, V. (2004). Sitios Históricos Tempranos De Carácter 
Defensivo. Sector Oriental De La Villa Rica (1550-1602). Chungara. Revista de Antropología Chilena, 36 (número especial 1), 175-186.

Moreno, F. (1897). Apuntes preliminares sobre una excursión a los Territorios del Neuquén, Río Negro, Chubut y Santa Cruz. La Plata: Museo de La Plata.

Nacuzzi, L. (1998). Identidades impuestas. Tehuelches, aucas y pampas en el norte de la Patagonia. Buenos Aires: Sociedad Argentina de Antropología.

Navarro Floria, P. (2012). Guillermo Cox y su Viaje en las regiones septentrionales de la Patagonia. En Cox, G. Viaje en las regiones septentrionales de la Patagonia 1862-1863 (pp. IX-XXXII). Santiago: Biblioteca Fundamentos de la Construcción de Chile.

Pérez, A. (2016). El registro arqueológico de la cuenca binacional del río Valdivia. La integración de su fuente, el lago Lácar, sector oriental cordillerano. En Nicoletti, M. A., Núñez, A. y Núñez, P. (Eds.). Araucania-Norpatagonia. Discursos y representaciones de la materialidad (pp. 157-193). Viedma: Editorial Universidad Nacional de Río Negro.

Pinto, J. (1988). Misioneros en la Araucanía, 1600-1900: Un capitulo de historia fronteriza en Chile. Temuco: Universidad de La Frontera.

Pinto, J. (Ed.) (1996). Araucanía y Pampas. Un mundo fronterizo en América. Temuco: Universidad de La Frontera.

Reyes, V. (2009). Microvariaciones en las cadenas operativas de producción cerámica durante el período alfarero tardío del área lacustre de los Andes occidentales, lat. $39^{\circ}$ sur, Patagonia septentrional. En Salemme, M., Santiago, F., Álvarez, M., Piana, E., Manzur, E. y Mansur, E. (Comps.). Actas VII Jornadas de Arqueología de la Patagonia. Una mirada desde el último confin, II (pp. 1159-1176). Ushuaia: Utopías.

Solari, M., Cueto, C., Hernández, F., Rojas, J. y Camus, P. (2011). Procesos territoriales y bosques en la cuenca del río Valdivia (siglos XVI-XIX). Revista de Geografia Norte Grande, 49, 45-62. https://www. redalyc.org/articulo.oa?id=30019961004

Treutler, P. (1861). La Provincia de Valdivia y los Araucanos. Santiago: Imprenta Chilena.

Urbina, S. y Adán, L. (2012). La Misión de Niebla: una instalación franciscana en la jurisdicción colonial de Valdivia. Informe Técnico Proyecto DID S-2011-34. Valdivia: Dirección de Investigación y Desarrollo, Universidad Austral de Chile.

Urbina, S. y Adán, L. (2014). Avances en la Arqueología de Valdivia. Boletin de la Sociedad Chilena de Arqueología, 43-44, 35-60.

Urbina, X. (2005). La Frontera "de Arriba” Chilena y el Camino de Chiloé a Valdivia. Temas Americanistas, $18,70-92$.

Urbina, X. (2009). La Frontera de Arriba en Chile Colonial. Interacción hispano-indígena en el territorio entre Valdivia y Chiloé e imaginario de sus bordes geográficos, 1600-1800. Valparaíso: Centro de Estudios Diego Barros Arana y Ediciones Universitarias de Valparaíso.

Van de Maele, M. (1968). Investigaciones Históricas - Investigaciones Arqueológicas. Mapa HistóricoArqueológico de la Provincia de Valdivia. Valdivia: Editorial Universidad Austral de Chile.

Vezub, J. (2009). Valentín Saygüeque y la "Gobernación Indígena de las Manzanas". Poder y etnicidad en la 
Patagonia Septentrional (1860-1881). Buenos Aires: Prometeo.

Vezub, J. (2017). El álbum de Encina y Moreno como libreta de viaje: antes, durante y después de los campos de batalla del Neuquén, 1883-2015. En Rodríguez Aguilar, M. I. y Vezub, J. (Eds.). Patrimonios visuales patagónicos: territorios y sociedades (pp. 125-146). Buenos Aires: Museo Roca, Ministerio de Cultura de la Nación.

Vignati, M. (1942). Iconografía Aborigen I. Los caciques Sayeweke, Inakayal y Foyel y sus allegados. Revista del Museo de La Plata (Nueva Serie), Sección Antropología, II, 13-48.

Villar, D. y Jiménez, J. (2003). La tempestad de la guerra: conflictos indígenas y circuitos de intercambio. Elementos para una periodización (Araucanía y las Pampas, 1780-840). Mandrini, R., y Paz, C. (Eds.). Las fronteras hispanocriollas del mundo indigena latinoamericano en los siglos XVIII-XIX. Un estudio comparativo (pp. 123-171). Tandil: CEHIR, Universidad Nacional del Comahue; Departamento de Humanidades, Universidad Nacional del Sur; IEHS, UNCPBA. 